

\title{
ERP 2.0, what for and how?
}

Bernard Grabot, Anne Mayère, Fabien Lauroua, Raymond Houé Ngouna

\section{To cite this version:}

Bernard Grabot, Anne Mayère, Fabien Lauroua, Raymond Houé Ngouna. ERP 2.0, what for and how?.

Computers in Industry, 2014, 65, pp.976-1000. 10.1016/j.compind.2014.02.017 . hal-01070519

\section{HAL Id: hal-01070519 https://hal.science/hal-01070519}

Submitted on 7 Oct 2014

HAL is a multi-disciplinary open access archive for the deposit and dissemination of scientific research documents, whether they are published or not. The documents may come from teaching and research institutions in France or abroad, or from public or private research centers.
L'archive ouverte pluridisciplinaire HAL, est destinée au dépôt et à la diffusion de documents scientifiques de niveau recherche, publiés ou non, émanant des établissements d'enseignement et de recherche français ou étrangers, des laboratoires publics ou privés. 


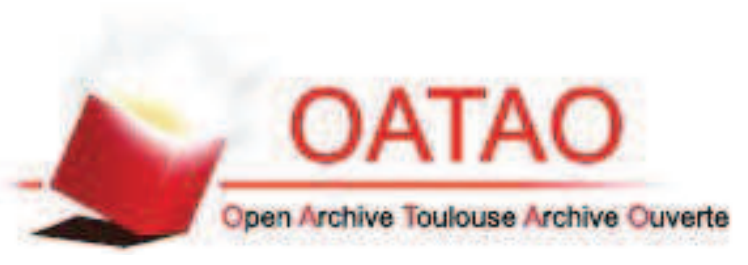

\section{Open Archive Toulouse Archive Ouverte (OATAO)}

OATAO is an open access repository that collects the work of Toulouse researchers and makes it freely available over the web where possible.

This is an author-deposited version published in: http://oatao.univ-toulouse.fr/ Eprints ID: 11945

To link to this article: DOI:10.1016/j.compind.2014.02.017

http://dx.doi.org/10.1016/j.compind.2014.02.017

\section{To cite this version:}

Grabot, Bernard and Mayere, Anne and Lauroua, Fabien and Houé Ngouna, Raymond ERP 2.0, what for and how? (2014) Computers in Industry, vol. 65 (nº). ISSN 0166-3615 


\title{
ERP 2.0, what for and how?
}

\author{
Bernard Grabot $^{\mathrm{a}, *}$, Anne Mayere ${ }^{\mathrm{b}}$, Fabien Lauroua ${ }^{\mathrm{c}}$, Raymond Houe ${ }^{\mathrm{a}}$ \\ ${ }^{a}$ Université de Toulouse, INPT, LGP-ENIT, 47 Avenue d'Azereix, BP 1629, F-65016 Tarbes Cedex, France \\ b Université de Toulouse, CERTOP, 114, Maison de la Recherche, 5, allées Antonio Machado, 31058 Toulouse Cedex 9, France \\ ' SAP On Demand Services, SAP France S.A., Défense Plaza, 23/25 rue Delarivière Lefoullon, La Défense 9, 92064 Paris, La Défense Cedex, France
}

\begin{abstract}
A B S T R A C T
The poor level of adoption of ERP systems is often considered as linked to a loss of social interactions between users of the ERP, together with the poor adaptability of these huge systems to local needs. Web 2.0 tools (including among others social networks, wikis, mashups and tags) aim at allowing a better interaction between a user and an Internet site, or between communities of users by means of a Web site. Using these tools in an industrial context appears now as a possible solution for addressing some of the problems of present information systems, and especially ERPs. Examples of such integration of Web 2.0 technologies in industrial practices are analyzed and the empiricism with which these experiences are usually conducted is underlined. In order to address this problem, we suggest a step-by-step method allowing to identify on which business processes performed by an ERP the Web 2.0 tools could be of interest, and investigate how to integrate the two worlds. This approach is illustrated on the SAP product Business By Design, which new version includes a set of configurable Web 2.0 tools.
\end{abstract}

Keywords:

Web 2.0

Enterprise 2.0

ERP 2.0

Social networks

\section{Introduction}

ERP (Enterprise Resource Planning) systems are now the backbone of the information system of any large organization. They have brought many crucial improvements in the companies, principally with their unique database avoiding data duplication, their "process" orientation, the integration of all the functions of the organization and the "best practices" they are carrying. Nevertheless, they have been and are still often criticized, with reasons including:

- their complexity, making it difficult for the users to have a global view on the processes in which they are involved,

- the temptation of centralized control that they bring into the organization [1],

- their "administrative" orientation, since they require the users to provide large amounts of data related to their daily work [2],

- the fact that their "best practices" are often more or less imposed to the users,

\footnotetext{
* Corresponding author. Tel.: +33 5624427 21; fax: +33 562442708 . E-mail addresses: bernard.grabot@enit.fr, rhoue@enit.fr (B. Grabot), anne.mayere@iut-tlse3.fr (A. Mayere), fabien.lauroua@sap.com (F. Lauroua).
}

- the standardization of the communication between employees that they may bring.

As a result, a huge literature exists on the reasons of a poor level of "adoption" of these tools by their users (see for instance $[3,4]$ ).

Since most of these problems deal with implication, communication, collaboration and knowledge sharing, including Web 2.0 tools in ERP systems has recently been an object of interest from an increasing number of researchers and practitioners. The term "Web 2.0" refers to a new way in which software developers and end-users started to utilize the Internet: that is, as a platform whereby content and applications are no longer created and published by individuals, but instead are continuously modified by all users in a participatory and collaborative fashion [5]. These issues are of course of critical interest for companies, which permanently seek for new ways to involve more deeply their employees, but also their customers and suppliers, into their business processes. Especially, it may be tempting to consider that these new applications could address some of the problems linked to the use of an ERP, often considered as creating social tensions within the companies.

Many experiences of implementation of 2.0 tools in companies have been recently documented (see a survey on such experiences in [6] for instance). Nevertheless, it can be noticed that most of 
these experiences are conducted in a quite empirical way, and that no clear methodology is usually followed for linking these new tools with the business processes of the ERP. In that context, this article has two main objectives:

- analyze recent experiments on the integration of Web 2.0 tools in industrial information systems,

- suggest the guidelines of a methodology which would improve the integration of these tools into ERP systems.

The article is structured as follows: in the second section are analyzed the various aspects of the Web 2.0 and it is shown how they may lead to the next generation of ERP, the "ERP 2.0". A survey of practical experiences aiming at introducing Web 2.0 functionalities in companies is provided in this section. In Section 3, requirements for an "ERP 2.0" are suggested and the case of the new ERP of SAP, Business By Design, ${ }^{1}$ which integrates some 2.0 tools as native functionalities, is presented. On that base, guidelines allowing to define how to practically use these tools for improving real business processes are suggested in Section 4. The first results of the use of this methodology on Business By Design are described in Section 5.

\section{Literature review: from Web 2.0 concepts and tools to the ERP 2.0}

\subsection{The concepts of Web 2.0}

According to Tim O'Reilly, one of the first persons who has tried to conceptualize around the Web 2.0 techniques, Web 2.0 can be characterized by user participation, transparency and network effects [7]. The Web 2.0 has not really very precise boundaries: it is composed of a set of concepts, principles and practices operationalized by a group of applications or technologies [8]. According to O'Reilly, the philosophy of the social application of Web 2.0 can be summarized by the following highlights:

- The Web as a platform: the Web becomes the universal platform for bringing new services to organizations and individuals.

- Harnessing collective intelligence: give access to expertise wherever it is, create collective knowledge and allow people to make group decisions.

- Data is the next "Intel inside": data, information and knowledge are sources of values if correctly structured and used.

- End of the software release cycle: software is delivered as a continuously improved service.

- Lightweight programming models: programming models should allow loosely coupled systems.

- Software above the level of a single device: other platforms than computers have to be considered (tablets, smartphones, etc.).

- Rich user experiences: provide new types of applications through the Web 2.0.

With a more technical point of view, Web 2.0 applications are characterized by the integration of a functionality that the Web "1.0" has not included in a systematic way: an advanced database management [8]. The Web 2.0 being based on large-scale data processing, Web 2.0 applications need user-friendly interfaces allowing to hide the complexity of powerful software tools dedicated to data collection and processing, using local or distant databases. According to Anderson [9], the value of an application becomes proportional to the value of the data processed by this

\footnotetext{
${ }^{1}$ http://www.sap.com/pc/tech/cloud/software/business-management-byde-
} $\operatorname{sign} /$. application (which seems to be consistent with the recent estimation of Facebook in the stock market for example).

\subsection{The main tools of the Web 2.0}

As already pointed out, many tools can be considered as following the Web 2.0 principles; nevertheless, Anderson [9] suggests that they can be grouped into seven categories, based on what they attempt to do:

1. Social networking

2. Aggregation services

3. Data mashups

4. Tracking and filtering content

5. Collaborating

6. Replicate office-style software in the browser

7. Source ideas or work from the crowd.

In the next sections are shortly described some of the most well known 2.0 tools. In order to emphasize their differences, a specific focus is set when relevant on the characteristics of the communication that they allow:

- the type of communication (from a provider to a reader or in both directions),

- its "synchronicity", i.e. whether their use requires a real time coupling between users or not,

- its "dynamicity", defined as the fast insertion and removal of information [10],

- the requirement of a user profile for using the considered tool,

- the possible types of relationship between users,

- the types of media exchanged,

- some typical uses of these tools.

\subsubsection{Social networking}

Social networking tools help to gather people having similar interests or motivations in order to share contents and to possibly produce common knowledge. A social network is composed by nodes (persons or organizations), interrelated by links. These interdependencies may denote friendship, competition, mutual interests, exchanges of contents or knowledge [11], but most of them require a formal acceptation for giving access to a profile (external users have to be approved as "friends"). Social media tools may aggregate multiple functionalities, some of them being provided by elementary 2.0 tools described in the next sections, like blogs, RSS, instant messaging or replication of office-style software. In practice, social network sites are web-based services allowing individuals to (1) build a public or semi-public profile within a bounded system, (2) define a list of users with whom they are in relation, and (3) view their list of connections and those made by the people with whom they are in touch [12]. They allow bi-directional exchanges, both in a synchronous (e.g. when chatting facilities are used) or asynchronous way (when displayed information is consulted). All types of media supports can be exchanged.

Borgatti et al. [11] suggest to distinguish continuous and discrete ties among persons involved in a social network. Continuous ties would concern long-lasting links (between members of a community based on similarities or social relations for instance) while discrete ties would consist in more opportunistic interactions (emails, invitations, etc.) and flows (information transfer).

For Borgatti et al. [11] and Wasmann and Spruit [13], what makes social networks unique is not that they allow individuals to meet strangers, but that they enable users to make visible their social network 




Fig. 1. Example of client service mashup [15].

Among many others, Facebook ${ }^{2}$ and LinkedIn $^{3}$ are known example of social networking tools.

\subsubsection{Aggregation services}

These tools allow to gather data from different sources in order to publish them in one place, mainly using RSS and syndication. Syndication is a process allowing to make accessible by a web site information coming from another site. RSS - Rich Site Summary (RSS 0.91 ) or RDF - Site Summary (RSS 0.90 and 1.0) or Really Simple Syndication (RSS 2.0) are families of XML formats used for the syndication of web content. Data are regularly collected on the source web site by dedicated software, installed on the client computer, and "pushed" to the user using the RSS format. The syndication norm that seems to be the most commonly used now is Atom, which allows to include several files with different formats in the same feed $[9,14]$. RSS is typically a mono-directional tool (from emitter to receiver), with no temporal synchronization of the human actors (provider and receiver of information). Dynamicity may be high (depending on the periodicity with which the provided information is updated). No control is performed on the subscribers (who can be considered as "followers" using the vocabulary of the blogs and micro-blogs). Only textual information is usually provided.

\subsubsection{Data mashups.}

In computer science, the term "mashup" is used for describing a compound image, built from several elementary images coming from different sources. In the context of the Web 2.0, mashups cover new applications, data or web pages built on the base of multiple and heterogeneous sources (images, but not only) for creating a new service. RSS feeds are possible means for building mashups.

Mashups can be classified in three categories [15]:

1 Client presentation mashups: this type of application gathers data from different sources (using RSS feeds) or generated by heterogeneous applications (using web services). The result is not always displayed graphically; it can be stored in a database or sent to be directly consumed by an application.

2 Client service mashups: in this type of mashup, visual contents coming from multiple sources are mixed for creating a new complex image according to a combination which is not perceived by the user, the origin of the image being hidden by a simple and unified interface (it is for instance the case for

\footnotetext{
2 https://en-gb.facebook.com/.

3 https://uk.linkedin.com/.
}

Google Map used in Fig. 1 for locating crime zones in Chicago [15]).

In this case, the mashup is built on the client, by dynamic interaction with the web sites providing the original information to be combined. Another solution is possible:

3 External service mashups, or "enterprise mashups". In this case, the mashup may be built by a local programme (written in Ruby, Perl, PHP, Flex or other programming languages) using a web service API (Application Programming Interface), available on the site of an information provider. The local programme is then able to combine this external information with an internal one (using for instance a local relational database). The source of information becomes therefore a client of the system on which the mashup takes place.

These mashups are generally composed of two layers. In the lower one can be found combinations of the two previous types of mashups, coming from internal or external sources. In the upper layer, a workflow produces and validates the results of collaborations in order to address the enterprise needs.

Mashups are typically mono-directional (from provider to consumer). Since the mashup process is automated, it does not require a synchronous presence of the provider and consumer. The dynamicity of this tool may be high but it is often used for providing rather stable information (like localization of places or events). No user profile is needed for the consumer, who can be a simple "follower".

\subsubsection{Tracking and filtering content}

These services keep track of, filter, analyze and allow search of data or multimedia content in the Web 2.0 , for instance in web pages and blogs (see hereafter). They can at the same time gather data (e.g. using RSS) and format it (e.g. using mashups) for an efficient display. These tools seem to be less discussed than the others in enterprise applications; we shall therefore not consider them with more details here. Google Alerts, ${ }^{4}$ IFTTT $^{5}$ and Yahoo! Pipes ${ }^{6}$ are often cited as the most efficient Tracking and Filtering tools [16].

\subsubsection{Collaborating}

This category groups, on one hand, tools allowing to build collaborative reference works, and on the other hand workgroup productivity tools.

\footnotetext{
${ }^{4}$ http://www.google.co.uk/alerts.

${ }^{5}$ https://ifttt.com/.

${ }^{6}$ http://pipes.yahoo.com/pipes/.
} 
Collaborative reference knowledge can be built using wikis: a wiki is a web site, the content of which can be edited by any user. It can be considered as a tool for knowledge creation and management. The nature of a wiki - open and incremental requires to provide functions for writing and correcting content, but also to manage versions. Like any advanced knowledge base, a wiki should allow to easily navigate through the elements of content and key words by links, such as hypertexts.

Although the power of wikis lies in their flexibility, their open access and ease of use may result in quality issues linked to errors or malevolent use [17]. In order to cope with these drawbacks, professional wikis often restrict the edition rights to "trusted and identified" users or groups [18], which is quite far from the original idea of open collaborative work.

Being collaborative tools, wikis imply an exchange between a community and a user/contributor. Nevertheless, this exchange is asynchronous. Wikis aim at capitalizing a stable knowledge: their dynamicity is therefore (voluntarily) low. Normally, no user profile is required from the contributors, and mainly text is exchanged. MediaWiki, DokuWiki ${ }^{7}$ or $\mathrm{PmWiki}^{8}$ are known tools allowing to create wikis.

The second set of tools allowing collaboration is made up of the groupware tools. Groupware tools allow a set of collaborators to work on the same task or project while located remotely from each other. These tools may include very different functionalities, like document storage or sharing, shared calendar, project management tools, but also tools allowing easy communication (e.g. video conferencing, instant messaging, forums). They are of course bi-directional, but depending on the precise tool used, they may allow synchronous (e.g. through video conferencing or instant messaging) or asynchronous (e.g. using forums) exchanges. All kinds of media may be involved in groupware tools. Google Apps ${ }^{9}$ or Microsoft SharePoint ${ }^{10}$ are groupware tools.

Instant messaging (also called "chat") tools allow a real time dialogue between participants and can be considered as a "synchronous forum" with or without pre-determined subject. By essence, they are bi-directional synchronous tools with a high dynamicity (the information exchanged often looses its interest quite rapidly). Depending on the system in which they are included (they can for instance be included in social networking tools), they may require or not a user profile. The exchanged media is mainly text, possibly images or short videos in some cases. Zopim $^{11}$ and Olark ${ }^{12}$ are known chat software for business applications.

Forums are web places allowing to exchange on a given subject, usually in an asynchronous way. They may be used as collaborative tools in a close community, for instance a group in a social network, but may also be used in a more opportunistic way for looking for a solution to a problem (see Section 2.2.7). Forums usually do not aim at capitalizing knowledge at long term like wikis, but at opportunistically solving a problem. Nevertheless, they can be available online for a long time and they may in that sense make some ad-hoc knowledge available. A difference with wikis is that the consistence of the content is not often formally checked. Instant messaging and forums, which may be considered as Web 2.0 tools on their own, may be

\footnotetext{
${ }^{7}$ https://www.dokuwiki.org/dokuwiki.

8 http://www.pmwiki.org/.

9 http://www.google.us/intx/en/enterprise/apps/business/.

10 http://office.microsoft.com/en-us/sharepoint/.

11 https://www.zopim.com/?lang=en.

12 http://www.olark.com/.
}

included in a large variety of compound 2.0 tools, including social media tools.

PhpBB, ${ }^{13}$ SMF, ${ }^{14}$ vBulletin ${ }^{15}$ are widely used open source forum software.

\subsubsection{Replicate office-style software in the browser}

These web tools allow the user to build one's own customized desktop on the base of data/information/services found on the Web. Sometimes close to filtering content tools (see Section 2.2.4), they may also use RSS and mashups. Seldom discussed in enterprise applications, they will not be considered in details here.

\subsubsection{Source ideas or work from the crowd.}

The objective is to seek ideas or solutions to problems, or get tasks completed by out-sourcing them to users of the Web. These tools may use various external sources like:

- Blogs and microblogs. A blog is a web site written on a specific subject by an individual or a group, which contains inputs (posts), organized in LIFO (Last In First Out) chronologic order. As for the inputs of a wiki, the inputs of a blog may be connected by hypertexts. They may include links to other sites, pictures, video or sounds for instance. A search engine may also be provided. The elements of the blog content are displayed and tagged with key words. The tags of the posts allow to navigate between posts from the same person or tagged by the same key words (see next section). InboxQ ${ }^{16}$ Flickr, $^{17}$ Google+ Circles $^{18}$ allow to create blogs.

A microblog may be considered as a short/instantaneous blog, since it consists in a very short message made available for "followers". Twitter ${ }^{19}$ is the most well known microblogging tool, up to the point that news exchanged by microblogs are often called "tweets" even if they are generated using other tools.

Blogs and microblogs are mono-directional (from provider to followers) and asynchronous tools. Even if they may be often actualized, blogs usually have a stability that the microblogs reject. The dynamicity of microblogs is therefore higher. Blogs and microblogs do not require user profiles. Blogs may use various media types (text but also image, videos, etc.) while the instantaneity of microblogs focus them on text (short text in the case of Twitter).

- Social bookmarking. A tag (or bookmark) is a key word (or text) added to a digital object for labelling it or storing an opinion on it. In opposition with traditional bookmarking, Web 2.0 bookmarking has two specific characteristics:

1. The tagging of bookmarking systems allows the users to create lists of tags and to store them on a distant server, in order to share them with other users. This functionality is more specifically called "social bookmarking" [19].

2. The categorisation of the tags allows a bookmark to belong to several categories, which permits to consider a digital object from different points of view.

Tagging has two main uses: distinguishing interesting information in a large database, or expressing an opinion (approval or criticism) on information. Tagging is a mono



13 https://www.phpbb.com/.

http://www.simplemachines.org/.

16 http://www.inboxq.com/.

18 https://support.google.com/plus/answer/1047805?hl=en-GB.

19 https://twitter.com/. 
Table 1

Characteristics of 2.0 tools.

\begin{tabular}{|c|c|c|c|c|c|c|c|c|}
\hline Colonne1 & $\begin{array}{l}\text { Type of } \\
\text { communic-ation }\end{array}$ & Synchronicity & Dynamicity & $\begin{array}{l}\text { Availability } \\
\text { of user } \\
\text { profile }\end{array}$ & $\begin{array}{l}\text { Type of social } \\
\text { relationship }\end{array}$ & Type of media & Typical use & Time frame \\
\hline Social network & Bi-directional & Asynch./Synch. & Any & Yes & Friends & $\begin{array}{l}\text { Text, image, } \\
\text { video, sound, etc. }\end{array}$ & $\begin{array}{l}\text { Build group, communicate } \\
\text { within the group }\end{array}$ & $\begin{array}{l}\text { Mainly } \\
\text { short-middle term }\end{array}$ \\
\hline RSS & One direction & Asynch. & High & No & Followers & Text & Get/provide info & Short term \\
\hline Mashups & One direction & Asynch. & High/average & No & Followers & Image, text, etc. & Aggregate info & Short term \\
\hline Wiki & Exchange & Asynch. & Low & No & Followers & Text & $\begin{array}{l}\text { Structure, store and } \\
\text { share info and knowledge }\end{array}$ & Middle-long term \\
\hline Groupware & Bi-directional & Asynch./Synch. & Any & Yes & Colleagues & $\begin{array}{l}\text { Text, image, } \\
\text { video, sound, etc. }\end{array}$ & Collective work & Any \\
\hline Chat & Bi-directional & Synch. & High & No & Friends/followers & Text & Instant communication & Real time \\
\hline Tagging & One direction & Asynch. & Average/low & No & Friends/followers & Text & Annotation & Middle term \\
\hline Blog & One direction & Asynch. & Average/low & No & Followers & $\begin{array}{l}\text { Text, image, } \\
\text { video, sound, } \\
\text { etc. }\end{array}$ & Information publication & Middle-long term \\
\hline Microblogging & One direction & Asynch. & High & No & Followers & Text & Dissemination of news & Short term \\
\hline Forum & Bi-directional & Asynch. & Average & No & Followers & Text & Information exchange & Middle term \\
\hline
\end{tabular}

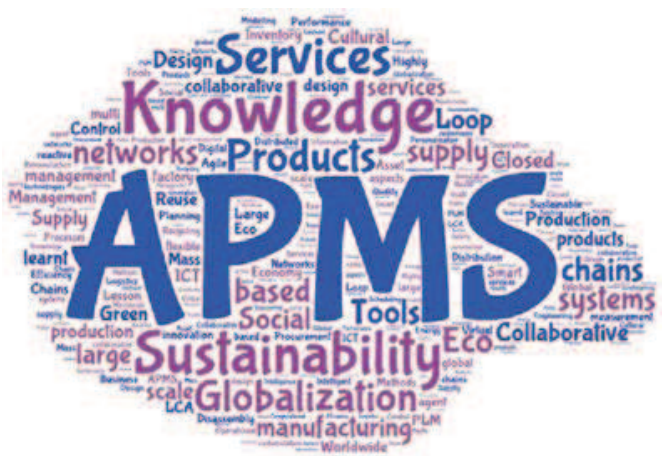

Fig. 2. Example of Tag cloud.

directional tool, used asynchronously. He may be open to any user or only to authorized people. The dynamicity only depends on the provider but it is usually a tool used for storing rather stable information.

Recently appeared, "Tag clouds" are also based on the principles of classification using tags of social bookmarking. In addition, these tools gather information on the frequency with which a tag is used. This allows to display the tags as a "cloud", the labels with the higher frequency of use being displayed with larger font size (see Fig. 2). These labels may be used as navigation tools.

Chipmark ${ }^{20}$ is an open source social bookmarking tool, while Delicious $^{21}$ or Digg ${ }^{22}$ are web services including bookmarking facilities.

The main characteristics of the listed tools are summarized in Table 1.

\subsection{Software for implementing Web 2.0 functions}

Software editors have already provided many tools for implementing Web 2.0 functions in organizations and companies. Well-known examples include:

- Mind Touch, a wiki-based enterprise-oriented social network platform to be integrated in existing applications in order to complete them with social features [20],

\footnotetext{
${ }^{20}$ http://www.chipmark.com/

21 https://delicious.com/.
}

22 http://digg.com/.
- Lotus Quickr, essentially used to share and manage collaborative content in the context of team working inside a company [21],

- Lotus Connections, the IBM "light" tool for managing social networks [22],

- Cyn.in [23], an open source "enterprise oriented" software available in SaaS mode (Software As A Service) allowing to store, search and organize files and collaborative contents,

- Novell Pulse [24], a platform of collaborative work allowing to share and co-edit files in real time, but providing also a unified reception box grouping emails and instant messages, allowing the users to visualize, sort and filter the contents of different services of social messaging [25],

- SAP Streamwork, collaborative tool for online decision making [26],

- Oracle Beehive [27], a "business oriented" integrated collaborative platform in which collaboration is oriented on three main domains: messaging (email, calendar, task management et contacts), synchronous collaboration (instant messaging, presence indicator, audio and video conference on the web) and team collaboration (work space with file libraries, wikis, team calendars and contextual research),

- ESME, an open source software developed by Siemens and SAP in order to provide a robust and incremental platform for microsharing and micro-messaging, allowing the users to have virtual meetings and exchange information in a "Business Process" context $[28,29]$,

- Mediawiki, a free open source wiki package written in PHP, originally developed for Wikipedia but now used in other wikis, mostly in non-profit organizations but also in some companies [30].

Even if it may be difficult to sort all the functionalities of these tools according to the categories suggested in Section 2.2, we have tried to roughly describe their main characteristics in Table 2 (not including Mediawiki, dedicated to wiki development).

In spite of their quite different functionalities, these tools all share the same limitation: they do not natively communicate with the main information system of the company, namely its ERP. This point will be illustrated in next section in which industrial applications of 2.0 tools are considered.

\subsection{Research works oriented on organizational and marketing studies}

Some research works have suggested ideas for the implementation of 2.0 tools in organizations; especially, social networks and their possible influence on organizations have induced a significant 
Table 2

Synthesis of the functionalities and technical characteristics of enterprise tools

\begin{tabular}{|c|c|c|c|c|c|c|c|}
\hline & Mindtouch & Oracle Beehive & Streamwork & Lotus Quickr & Cyn.in & Novell Pulse & ESME \\
\hline \multicolumn{8}{|l|}{ Functionalities } \\
\hline Blogs & $\mathrm{N}$ & $\mathrm{Y}$ & $\mathrm{N}$ & $\mathrm{Y}$ & $\mathrm{Y}$ & NA & $\mathrm{Y}$ \\
\hline Wikis & $\mathrm{Y}$ & $\mathrm{Y}$ & $\mathrm{N}$ & $\mathrm{Y}$ & $\mathrm{Y}$ & NA & $\mathrm{Y}$ \\
\hline RSS & $\mathrm{Y}$ & $\mathrm{Y}$ & $\mathrm{N}$ & NA & $\mathrm{Y}$ & NA & $\mathrm{Y}$ \\
\hline Update of pages and sections notification & Y email & Y email and SMS & $\mathrm{Y}$ & Y email & $\mathrm{Y}$ & NA & $\mathrm{Y}$ \\
\hline Integrated graphical display & $\mathrm{Y}$ & NA & $\mathrm{Y}$ & NA & $\mathrm{Y}$ & NA & $\mathrm{Y}$ \\
\hline Connectors with databases & $\mathrm{Y}$ & $\mathrm{Y}$ & NA & $\mathrm{Y}$ & $\mathrm{Y}$ & $\mathrm{N}$ & $\mathrm{Y}$ \\
\hline Advanced search tools & $\mathrm{Y}$ & $\mathrm{Y}$ & $\mathrm{N}$ & $\mathrm{Y}$ & $\mathrm{Y}$ & $\mathrm{N}$ & $\mathrm{Y}$ \\
\hline Microblogging & $\mathrm{N}$ & $\mathrm{Y}$ & NA & $\mathrm{Y}$ & $\mathrm{Y}$ & $\mathrm{Y}$ & $\mathrm{Y}$ \\
\hline User messenger & $\mathrm{Y}$ & $\mathrm{Y}$ & $\mathrm{Y}$ & $\mathrm{Y}$ & $\mathrm{Y}$ & $\mathrm{Y}$ & $\mathrm{Y}$ \\
\hline List of user tasks & $\mathrm{Y}$ & $\mathrm{Y}$ & NA & $\mathrm{Y}$ & $\mathrm{Y}$ & $\mathrm{Y}$ & $\mathrm{Y}$ \\
\hline Team calendars & NA & $\mathrm{Y}$ & $\mathrm{Y}$ & $\mathrm{Y}$ & $\mathrm{Y}$ & $\mathrm{Y}$ & \\
\hline Workflow & $\mathrm{Y}$ & $\mathrm{Y}$ & $\mathrm{Y}$ & $\mathrm{Y}$ & $\mathrm{Y}$ & $\mathrm{Y}$ & \\
\hline User awareness and profile identification & $\mathrm{Y}$ & $\mathrm{Y}$ & $\mathrm{Y}$ & $\mathrm{Y}$ & $\mathrm{Y}$ & NA & $\mathrm{Y}$ \\
\hline Open source & $\mathrm{Y}$ & $\mathrm{N}$ & $\mathrm{N}$ & $\mathrm{N}$ & $\mathrm{Y}$ & $\mathrm{N}$ & $\mathrm{Y}$ \\
\hline Mashups & $\mathrm{Y}$ & $\mathrm{Y}$ & $\mathrm{Y}$ & $\mathrm{Y}$ & NA & NA & $\mathrm{Y}$ \\
\hline MultiNlanguage & $\mathrm{Y}$ & $\mathrm{N}$ & $\mathrm{N}$ & $\mathrm{N}$ & $\mathrm{N}$ & $\mathrm{N}$ & $\mathrm{Y}$ \\
\hline \multicolumn{8}{|l|}{ Technical aspects } \\
\hline SaaS & $\mathrm{Y}$ & $\mathrm{Y}$ & $\mathrm{Y}$ & $\mathrm{Y}$ & $\mathrm{Y}$ & $\mathrm{Y}$ & $\mathrm{Y}$ \\
\hline Connectors via external applications & $\mathrm{Y}$ & $\mathrm{Y}$ & $\mathrm{Y}$ & $\mathrm{Y}$ & $\mathrm{Y}$ & NA & $\mathrm{Y}$ \\
\hline Multitenant & $\mathrm{Y}$ & $\mathrm{N}$ & NA & NA & $\mathrm{Y}$ & $\mathrm{Y}$ & $\mathrm{Y}$ \\
\hline Extension to web services & $\mathrm{Y}$ & $\mathrm{Y}$ & NA & $\mathrm{Y}$ & $\mathrm{Y}$ & $\mathrm{Y}$ & $\mathrm{Y}$ \\
\hline Programming languages for extensions & All web languages & NA & NA & NA & $\begin{array}{l}\text { All web } \\
\text { languages }\end{array}$ & NA & $\begin{array}{l}\text { ABAP, Java, } \\
\text { SQL, etc. }\end{array}$ \\
\hline Platforms and operating systems & Multi-platform & Multi-platform & Multi-platform & NA & LINUX & NA & Multi-platform \\
\hline
\end{tabular}

literature, interested in social and organizational aspects more than in software tools.

Critical factors for a real interest of the information available in social network sites are considered in [13] including affordance, collaboration, content, network effect, revenue model, trustworthiness, and user experience. For [31], the influence of usergenerated content depends on the content itself, but also on the creators of content and of their interactions. Hypotheses are for instance tested on the optimal number of contributors, the network embeddedness or the content age. The value of social software in manufacturing is discussed in [32]: for the author, the most important priorities in manufacturing are on faster innovation, disseminating operational best practices, and responding rapidly to customer service issues. These issues require an efficient collaboration between disparate teams split by location and functional area. In that context, enterprise social software should allow to build and maintain cross-functional communities. Taxonomies of inter organizational ties within a social network are analyzed in [33]. They are applied to the supply chain context for providing explanations on the characteristics of supply chain social networks.

In [34] are also suggested some ideas on what could bring 2.0 technologies to traditional organizations. The choice of a web strategy is considered as being based on six elements: objectives, customers, product, time, resources and tools. Since the needs vary with the company, a taxonomy of companies is taken from [35], based on customer intimacy, operational excellence and product leadership. These three characteristics are explained as follows:

- Customer intimacy is the aptitude to build bonds with the customer, understand the customer, taylor product and services. It requires customer loyalty.

- Operational excellence improves operational quality, efficiency, ease of purchase, and results in low prices and hassle-free services,

- Product leadership helps innovation and creation of new knowledge. It leads to creative environment and culture, and gives ability to commercialize new ideas quickly and provide state-of-the art products or services.

Twelve experts have then attempted to assess the interest of the key concepts of the Web 2.0, as defined in [7] (see Section 2), for each type of company. The result shows relatively limited differences: all the 2.0 principles seem to be of interest for a quite wide range of companies.

For a long time, the marketing literature showed an interest on how word-of-mouth drives consumer demand. Godes and Mayzlin [36] have for instance investigated how to measure word-ofmouth produced by TV shows, but social networks and blogs have recently dramatically increased the possibility to disseminate feelings and opinions on products amongst peers. Microblogging may be efficiently used for sharing consumer opinions: Jansen et al. [37] suggest that companies should use this 2.0 tool as part of their overall marketing strategy. As a further step, products can now be specifically designed for encouraging word-of-mouth contagion: see the concept of Viral Product Design, i.e. products explicitly engineered so that they are more likely to be shared amongst peers within social networks [38]. The marketing literature is of course interested in identifying the mechanisms of this contagion for better controlling it: for some authors, opinion leaders supplement professional knowledge. They have a specific influence on marketing social contagion and should be better identified [39]. For others, the concept of "influential individuals" is not enough for explaining social contagion: influence and susceptibility have to be considered at the same level [40].

\subsection{Experiences of use of 2.0 functionalities in companies}

Reports on experiences on the use of 2.0 tools in companies have first been sought in research papers, using Scopus and Google Scholar, with combinations of keywords like "2.0 AND enterprise", "enterprise 2.0" or "social network AND enterprise". Very few of the obtained research articles were in fact related to the implementation of 2.0 tools in the information systems of companies. We have so extended our search to Google with the 
Classification of the industrial applications according to Anderson's tool categories.

\begin{tabular}{|c|c|c|c|c|c|c|c|c|}
\hline & Company & $\begin{array}{l}\text { Social } \\
\text { networking }\end{array}$ & Aggreg. serv. & Data mashups & $\begin{array}{l}\text { Tracking } \\
\text { and filtering }\end{array}$ & Collaborating & $\begin{array}{l}\text { Off. style } \\
\text { software }\end{array}$ & Source ideas \\
\hline Adebanjo et al. [43] & Foodport & 1 & 1 & & & & & \\
\hline Barnes et al. [51] & $\mathrm{X}$ & 1 & & & & 1 & & \\
\hline Bourdier [48] & Dassault Systèmes & 1 & & & & 1 & & \\
\hline Bourdier [48] & Atos Or. & & & & & 1 & & 1 \\
\hline Brzozowski [54] & $\mathrm{HP}$ & 1 & 1 & & 1 & & & 1 \\
\hline Carbone et al. [59] & Bankinter & & & & 1 & 1 & & \\
\hline Carbone et al. [59] & Telefonica & & & & 1 & 1 & & 1 \\
\hline Carbone et al. [59] & Repsol & 1 & & & 1 & 1 & & 1 \\
\hline Cheng [61] & $\mathrm{X}$ & 1 & & & & & & 1 \\
\hline Dennison [70] & British Tel. & 1 & 1 & & & & & \\
\hline Dmitriev [69] & IBM & & & & & & & 1 \\
\hline Doan-Huy et al. [44] & WindRiver & 1 & & & 1 & 1 & 1 & 1 \\
\hline Ferron et al. [71] & FBK & 1 & & & & 1 & & 1 \\
\hline Goodbaum [42] & Channellock & 1 & & & & & & 1 \\
\hline Iversen [57] & IFS & & & & & & & 1 \\
\hline Lombardo [45] & Rhobi & 1 & & & & 1 & & 1 \\
\hline Lynch [55] & Fona & 1 & & & & 1 & 1 & \\
\hline Neil [62] & Equipois & & & & & 1 & & \\
\hline Neumann [64] & Ford & & & & & 1 & & \\
\hline Passant [53] & EDF & 1 & 1 & & & & & 1 \\
\hline Prasad [32] & Cisco & 1 & & & & 1 & 1 & \\
\hline Rosen [52] & Lockheed Martin & 1 & & & & 1 & & \\
\hline
\end{tabular}

same combinations of keywords, allowing us to access the blogs of many consultants on the field. We have selected the experiences published after 2010, even if some older ones have been occasionally kept when considered as typical. In order to give some legibility to the extracted list of examples, we have classified them according to their main objective. No selection has been performed, so a short subsection denotes a quite atypical application. Nevertheless, we shall see that the considered categories have both fuzzy boundaries and multiple intersections. A summary is also presented in Table 3, showing which of Anderson's categories [9] were addressed by these papers.

\subsubsection{The Web 2.0 as a tool to improve the relationships with the partners}

For companies, an already classical use of social networks is to create links with potential customers [41]. These tools may indeed complement the existing CRM software (Customer Relationship Management) but do not always communicate with them. Dedicated applications can be implemented on the web site of the company, or external social networks like Facebook, or blogs and topics in Twitter may be used. The case of Channellock Inc. is for instance cited in [42]: this company attributes much of its success to the use of social media platforms, namely a Facebook fan page, a blog and a Twitter handle, mainly for creating a direct contact with the customers. Nevertheless, no clear link with the CRM (Customer Relationship Management) module of their ERP is suggested. In [43] is reported the case of the company Foodport where 2.0 tools were installed for procurement, including a social network with an original "radar" view allowing to match companies and people having similar interests. Again, this feature allows to identify potential suppliers but is apparently not explicitly connected with the ERP. The Web 2.0 tools can also be more integrated with business processes, especially when used as interfaces for the customer or supplier support, like at WindRiver's [44]. The problem of the company was that the publishing process of their online support system (OLS), designed to support employees, customers, and partners on a unified development and delivery platform, was completely manual and required a high level of coordination between engineering, product management, and OLS staff. The lack of a centralized repository and the inability to dynamically update the documents was a problem. WindRiver took an Enterprise 2.0 approach to solve it: it decided to centralize support content in a content repository and utilize a Web 2.0 interface to deliver targeted content from the content repository, as well as from other enterprise systems. The new OLS front end, built using Oracle WebCenter, ${ }^{23}$ makes it possible for customers to personalize their online support workstation by subscribing to email and content alerts in order to get the information they want. Additionally, by planning to add further Web 2.0 features such as discussion threads and chat capabilities to the site, WindRiver aims to create a community of users that can provide each other with tips, best practices, and ideas for innovation in order to maximize their investment in Wind River technology. It can nevertheless be noticed that the content repository is distinct from the ERP database.

The Web 2.0 can also allow to create new types of relationships with existing partners, by complementing market places by "chat" facilities. The "RHOBI Live Marketplace" tool [45], for instance, allows aviation component buyers and sellers to find/offer components by keywords or part number, then to open multiple chat windows and discuss instantly with interested partners via live audio, instant messaging or emails. 2.0 functionalities can also be used for managing the customers' relationship. Many close applications in tourism are now well known, where Web 2.0 tools allow communications and personalized service at an individual basis. In these applications, firms and users generate customer value and customer relations through social networking, colearning, co-production and collaboration (see a survey in [46]). More generally, in a context close to B2B (Business To Business), the Web 2.0 can also allow to gather partners for creating an efficient supply chain (the term "Social supply chain" is suggested in [47]). The tools of the Web 2.0 may allow in that context to define "competence networks" helping to design the Supply chain: this direction is also explored by Adebanjo [43], who underlines the interest of these tools for the creation of "e-clusters" of SMEs.

\subsubsection{The Web 2.0 as a means to create an employees' network}

The Web 2.0 is seen here as a logical evolution of the Intranet of the company, allowing a better interactivity with the employees

${ }^{23}$ http://www.oracle.com/technetwork/middleware/webcenter/suite/overview/ index.html. 
[48-50]. Most of the applications listed hereafter aim at improving communication as a global goal, and not in the precise context of a business process executed by the ERP. Various types of messaging tools coupled with social networks have recently been tested for allowing the employees of different companies to communicate around their working activity. Nevertheless, this idea is not new: an application close to microblogging, implemented in a company for 10 years, is for instance described in [51]. Its functionalities are very close to those of Twitter, and are mostly used for public posting and direct messages. At Lockheed Martin, a social network called "Eureka" has been implemented for allowing the employees to create groups in a flexible way, in order to discuss their tasks [52]. 35,000 users have published their profiles on the internal enterprise network. Using Eureka, the employees of different locations can, for instance, compare their practices related to purchase activities. Another application providing, among others, wikis, tagging and RSS, is also mentioned at EDF (Electricité de France) [53], with the goal to create employees' networks allowing them to exchange knowledge. A similar case is Dassault Systèmes, mentioned in [48], where a platform of internal blogs aiming at facilitating the information transfer has been implemented in 2006. An experience at HP is described in [54] with the development and implementation of WaterCooler, a 2.0 platform grouping bookmarking, tagging, filtering, RSS and social network for allowing employees to identify people with useful expertise, then communicate with them.

A more precise experience is discussed in [55], concerning FONA, a company manufacturing flavours for the agro-food industry. The SocialText ${ }^{24}$ software has been deployed for allowing to create networks in order to manage projects in a fully decentralized way. The testing of flavours by employees is mentioned as an example. This activity was initially requiring a considerable effort when managed in a centralized way. The "testers" are now in direct "peer-to-peer" link using a dedicated social network allowing them to compare their feelings. The implemented tools include microblogging, social networks, widgets (reusable graphical pieces of interface), blogs and wikis. The possibility to simplify traditional "top-down" approaches by virtue of Web 2.0 tools, by allowing a more flexible distributed implementation, is also discussed in the 2007 McKinsey report [56].

It can be seen that the Web 2.0 may help to create employee's networks with different links with the business processes of the company:

- "loose" links, through the creation of virtual collaborative spaces allowing the employees to exchange information and thoughts in a rather free way (it is the case in most of the previous examples);

- "tight" links, the Web 2.0 directly supporting decentralized but formalized processes (see the case of FONA). In that case, the Web 2.0 tools are used as a flexible workflow for controlling in a distributed way processes that are too specific for being explicitly monitored by the ERP.

\subsubsection{The Web 2.0 as a tool for knowledge coproduction}

The main objective of companies using Web 2.0 techniques is often knowledge coproduction [94]. In this case, tools oriented on content management are of specific interest [57], because of their capacity to provide a shared space allowing knowledge codification. Knowledge is often formalized in a textual way, even if it can be illustrated by other media (image or video for instance). The case of Atos Origin, where a wiki dedicated to the creation of a "trade encyclopaedia" was introduced, is for instance mentioned

\footnotetext{
24 http://www.socialtext.com/.
}

in [48]. An experience in Emerson Process Management is cited in [57]: the company uses wikis for helping its companiescustomers to facilitate the transition between old and new generations of employees. For instance, mini-wikis have been incorporated in an alarm management system, in order to capture the actions performed during crisis or abnormal situations. This experience is a rare case of a Web 2.0 application formally integrated into an industrial process, this process being nevertheless quite specific. The case of the improvement of an on-line help is also mentioned in [57]. It can be noticed that all these experiments seem to consider that allowing the employees to exchange information in a textual way is enough for knowledge coproduction [58]. An important problem is nevertheless to give a shared "sense" to the exchanged information, and to be able to perform inference, which requires an "explicit" knowledge. Business intelligence tools are for instance proposed in that purpose in [13], but semantic web technology is a solution more often considered, especially for the textual part of the exchanged information.

Passant [53] describes for instance an experiment performed at EDF, which explicitly considers the question of making exploitable the information recorded in a wiki. The problem in EDF was that knowledge created using a recently installed wiki could not be easily understood by computers, free-tagging leading to heterogeneity and ambiguity, which complicates the search for relevant content. To solve this problem, a solution using semantic web technologies was developed, relying on a mediation system between services and users. This mediation system provides a common model for meta-data and for document content, using ontologies, plugins for existing tools to create data according to these ontologies, a central storage system for these data, and services to enrich information retrieval and data exchange between components.

As shown by the EDF example, semantic web technologies may be combined with Web 2.0 tools in order to improve the understanding of the exchanged information. Carbone et al. [59] suggest to use the term "Enterprise 3.0" for an Enterprise 2.0 framework augmented by semantic technologies, coming from the semantic web, in order to obtain computer-readable representations of knowledge. The authors show that, once a text has been collected thanks to Web 2.0 tools, and ontologybased analysis can provide a semantic contextualization of content support tasks, and can help to establish a clear exchange between users. Three experiments of the same tool in Spain are described: in Bankinter (a financial institution), an "idea management" system based on 2.0 tools allows to foster collaboration for innovative ideas filtering, reducing the amount of work required for evaluation. In Telefonica I + D (R\&D), the same system is used to allow employees to publish proposals in a blog-like intranet. Comments and votes are used for ideas refinement and filtering. In Repsol, unlike the two previous experiments, the system is used to create an innovation culture by giving to thousands of employees the opportunity to suggest ideas inside a system able to recognize semantic similarities between proposals. It can be noticed that this idea was already present in [9].

On the opposite, the conclusions of the McKinsey report [56] seem to advocate for the interest of collecting via wikis unstructured or anecdotal information that the company could hardly capitalize by other means. In this case, the Web 2.0 tools would complement existing knowledge engineering techniques, but would not replace them.

It is again noticeable that these applications do not show the possible connection with the ERP of the companies: the produced knowledge undoubtly helps to make decisions, but is not explicitly integrated in the ERP. 
2.5.4. The Web 2.0 as a way to open the company on its environment

Applications aiming at improving the communication between the company and its partners (customers and suppliers), already addressed in Section 2.5.1, are not considered here: this category includes more original experiments aiming at creating a link between the company and external entities with whom it does not have formal working relations. In [57] is for instance described another functionality implemented at IFS: the access to "external users' wisdom", in order to allow the employees to be aware of practices promoted by other companies. We are close here to benchmarking approaches, which have had a great success in many large companies some years ago. The possibility for employees of different companies to exchange information is also mentioned as a need in [60]. Nevertheless, the motivations of the exchanges so that their context remain unclear in the interviews analyzed in this study. In [61], the role of social networks in the adoption of new practices is analyzed in Taiwanese industries: firms identify and choose new practices through external contacts provided by social networks. Web 2.0 tools are here considered as a way to create a learning process on the base of external wisdom. The interest of the 2.0 tools for allowing information and knowledge to flow in and out of the organization, stimulating creation of knowledge and innovation, is also underlined in [34].

\subsubsection{The Web 2.0 as a tool for collaborative work}

In a more structured way than in Section 2.5.2, many applications have been proposed in order to turn web sites into collaborative working platforms using Web 2.0 functionalities [62]. The term "Collaboration 2.0" is suggested in [63] for these applications, more structured than classical wikis and often including a workflow (the possible links between wikis and workflows are investigated in [64]). "Collaboration 2.0" has also been promoted for collaborative product development [65]. Sharing documents is not always enough for allowing collaboration: Equipois Inc. wanted its R\&D lab in Philadelphia to collaborate with the rest of the company [62]. They used first Google Gmail ${ }^{25}$ and Google Docs ${ }^{26}$ for information sharing but wanted a SaaS (Software as a Service) for providing a central repository of documents, web meeting facilities, calendar events management, a company intranet so that facilities for managing internal businesses. The company adopted Central Desktop ${ }^{27}$ in that purpose. Ford has also conducted interesting experiments on this field: according to Neumann [64], Ford "has turned many of its processes into web services". The examples given are nevertheless limited: the factory manager can for instance publish the planning and may authorize online improvements. Cisco uses its own social software solution, Cisco Quad, ${ }^{28}$ for team working; the platform includes voice calls and web conferences [32]. Virtual sales communities have been created in the company thanks to social networking, allowing to "click to collaborate" from desktop or mobile devices. Prasad [28] also mentions "a company" using social software for enabling process technicians and maintenance engineers facing a downtime event to quickly search for colleagues. The platform allows to identify available expert in real time and to start audio/web/video collaboration sessions.

In a more limited but operational way, "social bookmarking" tools like Delicious, ${ }^{29}$ "My Web 2.0"30 from Yahoo or Dogear [66] allow people who use large information spaces to remember and retrieve items that they have previously found and thought to be

\footnotetext{
25 http://mail.google.com.

26 http://docs.google.com

27 http://www.centraldesktop.com/.

28 http://www.cisco.com/web/products/webexsocial/index.html.

${ }^{29}$ https://delicious.com.

30 https://info.yahoo.com/privacy/sg/yahoo/myweb/.
}

interesting, including associated notes. Some industrial applications of these tools are mentioned, but again, the problem is to identify the industrial processes in which these functionalities may bring an added value.

IBM [49], in a white paper intended for information system managers, sees above all the Web 2.0 and the industrial social networks as a means to make experiences and knowledge disseminated within the company more accessible, i.e. as new means to collaborate and facilitate interaction between employees. Deeper findings on what social networking brings to team working are given in [67]. Another - indirect - goal of the integration of the Web 2.0 functions to the existing processes is to decrease the reluctance of the collaborators for the adoption of a centralized information system like an ERP, often seen as replacing social links by pre-formatted workflow-based exchanges of data. The Web 2.0 tools may in that case help to re-create this missing social link in the digital world [68]. Nevertheless, in all the previously listed applications, it can be seen that the way the created social groups are involved in the business processes managed by the ERP remains implicit.

\subsubsection{The Web 2.0 as a means to increase individual productivity}

To a lower extent, some authors have also paid attention to the increase of individual productivity allowed by Web 2.0 tools. For instance, Dmitriev [69] suggests an annotation system for improving the performance of the search engines in company's Intranets. This technique, close to tagging (it consists in adding notes to the already visited pages), has been applied to the Intranet of IBM, but is again not included in the ERP.

\subsubsection{The Web 2.0 as a social experiment in the company}

A rather atypical experiment is mentioned in [70]: the British Telecom company has initially noticed that 4000 of its employees were participating to a Facebook group called "BT". In spite of internal resistances at high level, the company decided to launch a similar internal initiative, apparently without any precise idea on its finality (which is a clear difference with the applications listed in Section 2.5.2, focusing explicitly on creating "work oriented" links between employees). A comprehensive set of tools including wiki/blog/social network was installed in the company, and was massively adopted by the employees, with 1500 blogs opened in few days. A "tagging" system allows to publish subjects in a clear way, the result being a set of exchanges which rapidly turns into "conversation". Nevertheless, no link seems to have been created between the installed software and the existing information system of the company. Again, it can be noticed a rather empirical use of the Web 2.0 for connecting people, without an explicit link with the business processes.

A similar experience is described in [71], with the implementation of a 2.0 platform, Taolin, in the research foundation "Fundazione Bruno Kessler" (FBK) in Italy: again, and even if the initial motivation of the project was to allow researchers to easily access to the knowledge of their colleagues, the system was progressively deployed without any clear suggestion on what should be done with it. No formal link with the ERP is suggested.

In all cases, we can notice that if interesting experiments have been performed, they seem to have be most of the time conducted in a rather ad-hoc manner: the reasons that brought to choose the selected activities for implementing Web 2.0 functionalities remain quite empirical, and close to good sense when mentioned, like the necessity to create exchanges between distant people, or allowing them to work together.

\subsubsection{Synthesis of the use of Web 2.0 tools in companies}

The various cases discussed in previous sections show the growing interest of the companies for the 2.0 tools. In our opinion, they also show that the performed experiments have seldom 
Table 4

2.0 tools used by companies [74]

\begin{tabular}{lllll}
\hline & 2009 & 2010 & 2011 & 2012 \\
\hline Online video conferencing & N/A & N/A & N/A & $60 \%$ \\
Social networking & $28 \%$ & $40 \%$ & $50 \%$ & $53 \%$ \\
Blogs & $32 \%$ & $38 \%$ & $41 \%$ & $43 \%$ \\
Collaborative document editing & N/A & N/A & N/A & $43 \%$ \\
Video sharing & $31 \%$ & $33 \%$ & $38 \%$ & $41 \%$ \\
RSS & $28 \%$ & $30 \%$ & $30 \%$ & $29 \%$ \\
Wikis & $25 \%$ & $27 \%$ & $25 \%$ & $26 \%$ \\
Microblogging & $12 \%$ & $19 \%$ & $23 \%$ & $25 \%$ \\
Podcasts & $23 \%$ & $25 \%$ & $24 \%$ & $25 \%$ \\
Tagging & $14 \%$ & $18 \%$ & $19 \%$ & $20 \%$ \\
Mashups & $9 \%$ & $11 \%$ & $9 \%$ & $8 \%$ \\
\hline
\end{tabular}

resulted in the integration of these tools to existing business processes: the 2.0 tools are most of the time used as additional, "on the side" systems, used for accessing more easily external knowledge or information. They are not really considered as tools deserving that more efficient business processes are re-designed around them, for taking full benefit of their possibilities.

The listed experiments are summarized in Table 3 according to the seven functionalities suggested by Anderson [9]. As expected, it is clear that many applications aim at creating links between people through social networks, allowing them to collaborate and get ideas for distant experts. In our opinion, the absence of references to operational tools like mashups should not be misinterpreted: Anderson's taxonomy mixes operational tools (like mashups) and quite generic functionalities (like collaboration), while the case studies, often briefly reported in blogs, do not usually give implementation details.

\subsection{Surveys of consultancy firms}

Several reports provided by consultancy firms have also tried to quantitatively assess the industrial implementations of the 2.0 technologies, e.g. [6,56,72-74].

In 2011, the main field departments in which "Enterprise 2.0" efforts were actively engaged were [6]:

- Business development/sales (47\%),

- Marketing/communication (43\%),

- Operations/IT (38\%),

- Innovation/product development (31\%),

- Customer support (25\%),

- Professional services (23\%),

- Human resources (21\%),

- Finance/administration (8\%).

In Table 4 are summarized the percentages of companies having answered to McKinsey surveys between 2009 and 2012 that were using the various categories of Web 2.0 tools [74] (the "N/A" correspond to new questions). It can be noticed that even if the implementation of some tools is stable (RSS, mashups, podcasts), the development of others is expending (especially social networking). These numbers are consistent with the applications discussed in Section 2.5, that also set a great emphasis on the implementation of social networking tools, collaboration tools and blogs. Online conferencing tools are distinguished in Table 4, but are often integrated in collaborative tools in the experiments described in Section 2.5.

In Table 5 are shown the benefits of the 2.0 tools as expressed by the executives of the companies, classified according to three types of applications: internal; involving customers; involving partners and suppliers. We can find here some of the reasons for
Table 5

Benefits of the use of 2.0 tools [74].

\begin{tabular}{lllll}
\hline & 2009 & 2010 & 2011 & 2012 \\
\hline Internal & & & & \\
Increasing speed to access knowledge & $69 \%$ & $77 \%$ & $74 \%$ & $71 \%$ \\
Reducing communication costs & $56 \%$ & $60 \%$ & $58 \%$ & $66 \%$ \\
Reducing travel costs & $41 \%$ & $44 \%$ & $40 \%$ & $55 \%$ \\
Increasing speed to access internal experts & $44 \%$ & $52 \%$ & $51 \%$ & $48 \%$ \\
Increasing employee satisfaction & $37 \%$ & $41 \%$ & $40 \%$ & $42 \%$ \\
Customers & & & & \\
Increasing marketing effectiveness & $54 \%$ & $63 \%$ & $69 \%$ & $65 \%$ \\
Increasing customer satisfaction & $44 \%$ & $50 \%$ & $47 \%$ & $51 \%$ \\
Reducing marketing costs & $39 \%$ & $45 \%$ & $43 \%$ & $47 \%$ \\
Reducing travel costs & $33 \%$ & $29 \%$ & $24 \%$ & $43 \%$ \\
Reducing customer-support costs & $33 \%$ & $35 \%$ & $28 \%$ & $34 \%$ \\
& & & & \\
Partners, suppliers and external experts & & & & \\
Reducing communication costs & $50 \%$ & $53 \%$ & $61 \%$ & $63 \%$ \\
Increasing speed to access knowledge & $53 \%$ & $57 \%$ & $65 \%$ & $62 \%$ \\
Reducing travel costs & $40 \%$ & $38 \%$ & $37 \%$ & $54 \%$ \\
Increasing speed to access internal experts & $43 \%$ & $40 \%$ & $50 \%$ & $48 \%$ \\
Increasing satisfaction of partners, suppliers & $38 \%$ & $45 \%$ & $42 \%$ & $42 \%$ \\
$\quad$ and ext. experts & & & & \\
\hline
\end{tabular}

the use of 2.0 tools mentioned in the examples of Section 2.5: better access to internal or external knowledge and better communication especially, with a specific interest for marketing issues, as denoted in Section 2.4. While percentages reporting certain benefits (like access to external knowledge) are quite stable at a high level, increased shares cite cost-cutting benefits in 2012 [74], whereas 2 years earlier, the ChessMedia report [6] was underlining that $70 \%$ of the companies were unable to find direct performance improvements linked to the implementation of 2.0 tools.

We shall see in next section what could be required for making operational the "Enterprise 2.0" paradigm, by integrating Web 2.0 tools within the main information system of the companies: their ERP.

\subsection{The "ERP 2.0"}

ERPs are usually considered as highly structured information systems. The flexibility that they could gain from an integration with Web 2.0 tools is sometimes discussed in the literature on ERP adoption [75,76], but the possible combination of the two systems is seldom analyzed in details. For some authors, the integration of tools like wikis and blogs into an ERP is firstly useful for "channeling" a tendency that may lead to a loss of productivity of the employees and to security breaches if not correctly addressed [77]. Nevertheless, according to a study conducted for IFS (a company developing additional components for ERPs) [78], "manufacturers want more integration between social networking tools and their ERP systems". 62\% of the persons interviewed during the study estimate that the ERP should formalize and record the knowledge of experienced engineers. Web 2.0 tools could be of great help in that purpose. Nevertheless, the Web 2.0 applications described in previous sections are most of the time loosely related to the ERP: they may deal with "objects" managed by the ERP (orders, products, articles, etc.), but no formalized relationships allow the results of 2.0 based-activities to be automatically inserted in the ERP; the two systems remain disconnected. The main reason is that the Web 2.0 applications collect unstructured data (typically, text) that can hardly be stored and processed in the ERP highly structured databases. This point justifies for instance that researchers recently suggested to introduce Natural Language Processing in Enterprise Information Systems in order to be able to 


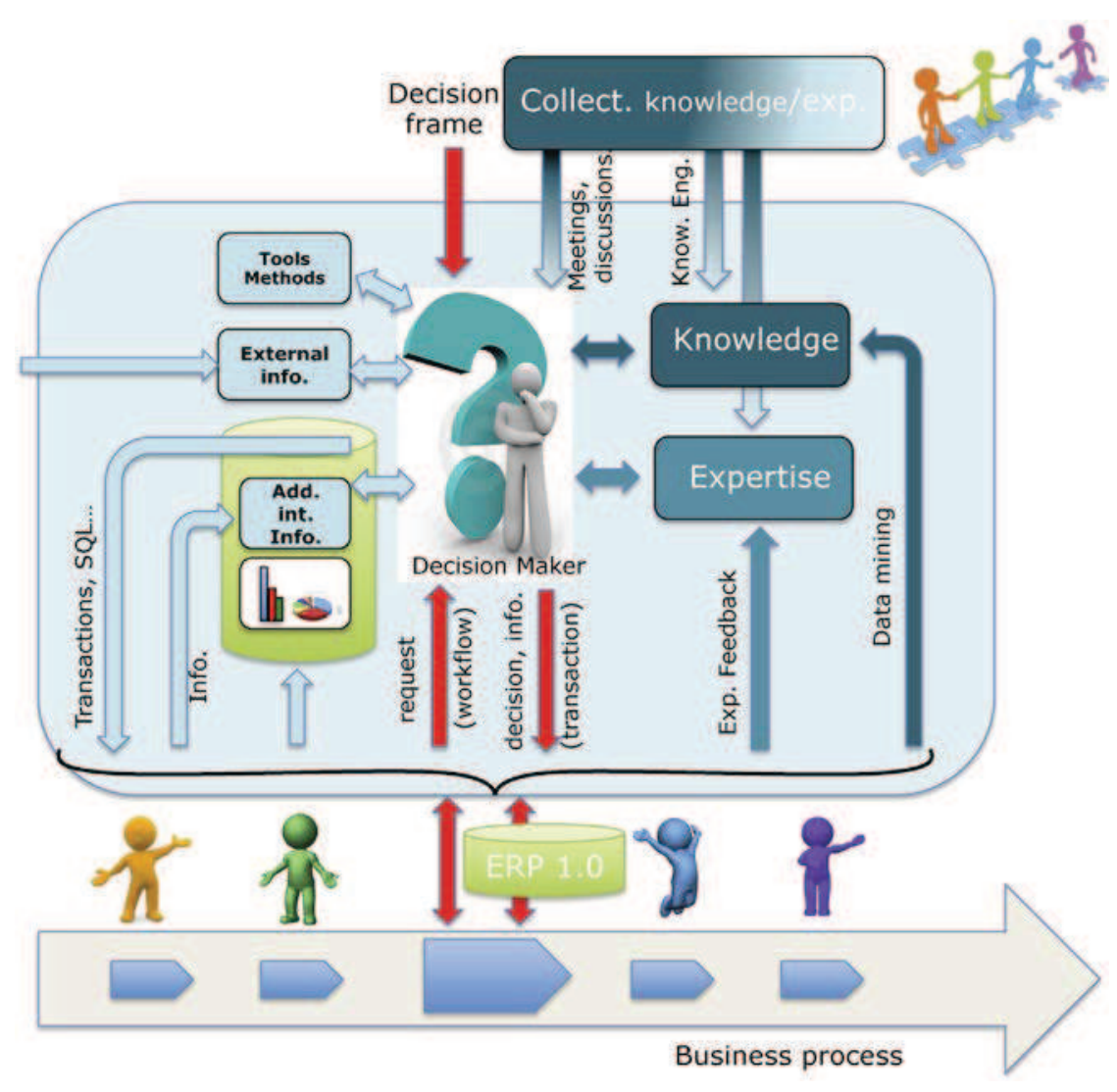

Fig. 3. Business process, decision making and "ERP 1.0".

analyze texts obtained from sources like emails or social media [79].

For some authors, the 2.0 functionalities should participate to re-create in the company the social links damaged by the standardization of the exchanges between actors that may follow the ERP implementation [80]. Nevertheless, this discourse often stays at a theoretical level, without real operational guidelines. What could be an "ERP 2.0" is discussed in next section.

\subsubsection{The classical ERP: "ERP 1.0"}

First of all, let us try to make clearer the distinction between information and knowledge. Information is often defined as "contextualized data", and knowledge as a "justified true belief" [81]. Since truth is a fuzzy concept, some authors prefer to define knowledge as "a dynamic human process of justifying personal belief towards the truth" [81]. According to Ackoff [82], information is composed of data processed to be useful, and provides answers to "who", "what", "where", and "when" questions, while knowledge is a pattern connecting data and/or information, answering to "how" questions. For Davenport and Prusak [83], knowledge is "a mixture of organized experiences, values, information and insights offering a framework to evaluate new experiences and information". Without any ambition to close the debate, we shall focus here on more operational definitions: information is considered as expressing a contextualized fact of the real world (true or false), while knowledge (on a given topic) provides a way to process existing information (on this topic) for making an hypothesis on an unknown information. As a consequence, knowledge is for us a mix of basic information and inference mechanism allowing to produce an unverified information.

Before the generalization of ERPs, the information systems of the companies were mainly built on the base of legacy systems, linking heterogeneous pieces of software by ad-hoc interfaces. ERPs have provided major improvements to this unsatisfactory situation, mainly thanks to their large functional coverage allowing to integrate all the functions of the company, but also by their workflow allowing to automate the information flow between actors, providing a synchronization of the execution of the business processes.

In Fig. 3 is suggested a model of the decision making activity in the context of business processes controlled by an ERP. According to the GRAI conceptual model of decision [84], a decision centre (which is assimilated in Fig. 3 to a decision maker (DM), even if the same decision maker may control several decision centres) receives a decision frame from the upper decisional levels, including objectives and means. Business models define the role of the decision centres in the business processes, these business processes being then executed by human actors in interaction with the ERP. Business processes are usually defined as networks of activities [85] according to formalisms sometimes promoted by a given ERP (e.g. DEM for BaaN ${ }^{31}$ or ARIS for SAP ECC ${ }^{32}$ ). The result of this modelling phase is often a quite analytical and detailed view on the processes, within which, according to ISO 9000 standards, the competence of each human actor in the process should be justified.

In order to make his decisions, the DM may use various sources of information (left part of Fig. 3): a dashboard dedicated to his decisional activity [84], but also various kinds of additional information, accessible using transactions on the ERP or SQL queries on the database. The DM may also need external information; the ERP does not provide any support in that

\footnotetext{
31 http://www.baandem.com/.

32 http://www.softwareag.com/corporate/products/aris/bpa/products/sap/overview/default.asp.
} 
purpose. The DM may use various tools and methods for preparing his decision, such as simulation tools or tools of Total Quality Management.

Not only information is required for making a decision, but also knowledge or at least expertise (right part of Fig. 3). This knowledge/ expertise may be personal (included in the square area of Fig. 3) or may be provided by other actors, also involved in the business process (as suggested in Fig. 3), coming from other processes, or even other companies. These actors may be involved through discussions, meetings, benchmarking or consultancy for instance. Various methods and tools may help to structure expertise (e.g. experience management [86]) or knowledge engineering (e.g. using data mining) [87]).

In our opinion, the ERP "1.0" only provides support to the DM for gathering internal information, but does not easily allow to gather external information, and above all, external experience and knowledge. In a context where business processes are often defined as sequences of rather separated activities, an important task of the human actor is therefore to communicate with the other actors for making decisions based on shared knowledge, considered nowadays as a key point for adding values to processes [88].

\subsubsection{First considerations on the ERP}

Even if a Google search with "ERP 2.0" returns several hundreds of results, it is interesting to notice that the same search under Scopus only returns a small set of research articles having both "ERP" and "Web 2.0" or "Enterprise 2.0" in their keywords: some research works indeed try to show how to integrate the two technologies, but very few of them use yet the term "ERP 2.0", even if it is now widely spread in the enterprise world. Most of these papers, like [75], insist on the necessary synergy between ERP and Web 2.0 tools in the next generation of software. Wang et al. [76] investigates the interest of the combination of the two types of systems on four case studies, without clear generalization. On the other hand, the already mentioned report from IFS [57] gives the results of a study conducted through interviews of 325 executives in North America on what they expect from the ERP 2.0. Even if most of them see the potential of social functionality embedded in ERPs (58\%), their interest is yet focused on very classical features, especially communicate within the enterprise, document business to support lean initiatives, and capture the tacit knowledge of senior employees.

Kimberling [89] and Wang et al. [76] asked the question of the possibility of alignment of these two technologies: on one hand, 2.0 technologies group informal and unstructured social media tools allowing anyone to say anything without real control or structure, e.g. social networks or wikis. On the other hand, ERPs are large and structured enterprise systems controlling surrounding master data, security profiles, and standard workflows. The first ones are simple, flexible, and supportive of a flat organization, while the second ones are consistent with a larger and more controlled infrastructure.

Kimberling [89] suggests to combine the weak and strong points of the two worlds, according to four main ideas:

1. Make ERP systems more flexible and social interactions more structured: the 2.0 technologies should allow the ERP to remain aligned with evolving processes, if how to use these tools is clarified.

2. Focus on the strengths of each technology: ERP should be dedicated to back office control and standardization, 2.0 for customer interaction and capture of undocumented knowledge.

3. Define the business blueprint: clarity around business processes, organizational roles and responsibilities, and performance measures should ensure that the system is designed to support business processes and tested accordingly.

4. Address organizational change management: even if they should give more flexibility and support to the employees, introducing 2.0 tools is another change that will again disturb the organization.

Hawryszkiewycz [90] suggests more precise guidelines for an evolution of the corporate information systems towards a real 2.0 version. He describes examples of possible links between 2.0 functionalities and business processes, mainly oriented on collaborative architectures for knowledge sharing. According to him, the main motivations for including 2.0 tools in business processes are on the one hand that the links between the different processes are constantly changing and need to be maintained, and on the other hand that "knowledge workers" require support to permanently update their social work connections, in order to quickly adapt to changing situations. In that purpose, Hawryszkiewycz [90] suggests the architecture of an "Enterprise Social Network" based on the identification of roles, sources of knowledge and decision to make, assisted by a "collaborative infrastructure platform" including communication facilities, blogs, wikis and team agendas.

The main idea of this work is to link at an early stage of process design the business activities and the knowledge model enabling these process activities. A social organization built on the base of the roles of the "knowledge workers" is then associated to this model, the 2.0 infrastructure allowing collaboration between roles within the business activities.

On the base of this emerging literature and on the experiments already performed on the use of 2.0 tools in companies, what could be a real "ERP 2.0" is discussed with further details in the next section.

\section{Requirements for the ERP 2.0}

\subsection{Generic requirements}

On the base of Kimberling and Hawryszkiewycz's proposals $[89,90]$, we suggest in this section to formalize what could be an ERP 2.0 (see Fig. 4) in comparison with what we can call the "ERP 1.0", depicted in Fig. 3.

The ERP 2.0 should break the silos between the automated and human activities of the business processes, by putting a clear emphasis on a seamless access to collective knowledge on different time horizons. Even if the "1.0" functionalities of the ERP are still required (communication between ERP and single user through transactions), the working area of each actor should include a larger workspace for collective working, managed inside the ERP.

Let us re-visit the 2.0 tools in the ERP context, defined by exchanges of short to long term information and knowledge in a synchronous or asynchronous way.

As a first point, information access, either internal or external, can be included in the ERP using RSS (for harvesting the information) and mashups (for formalizing aggregated information), these tools providing customization facilities to each user.

Information/knowledge can be stored in or transported by the ERP in quite different ways using the other 2.0 tools:

- tags provide asynchronous ways to allow a user to store information/knowledge related to the content of the ERP, both for personal or collective use. Tags are supposed to stay valid for a long period of time.

- tweets provide an asynchronous mean for disseminating short term/asynchronous information or knowledge. They are clearly 


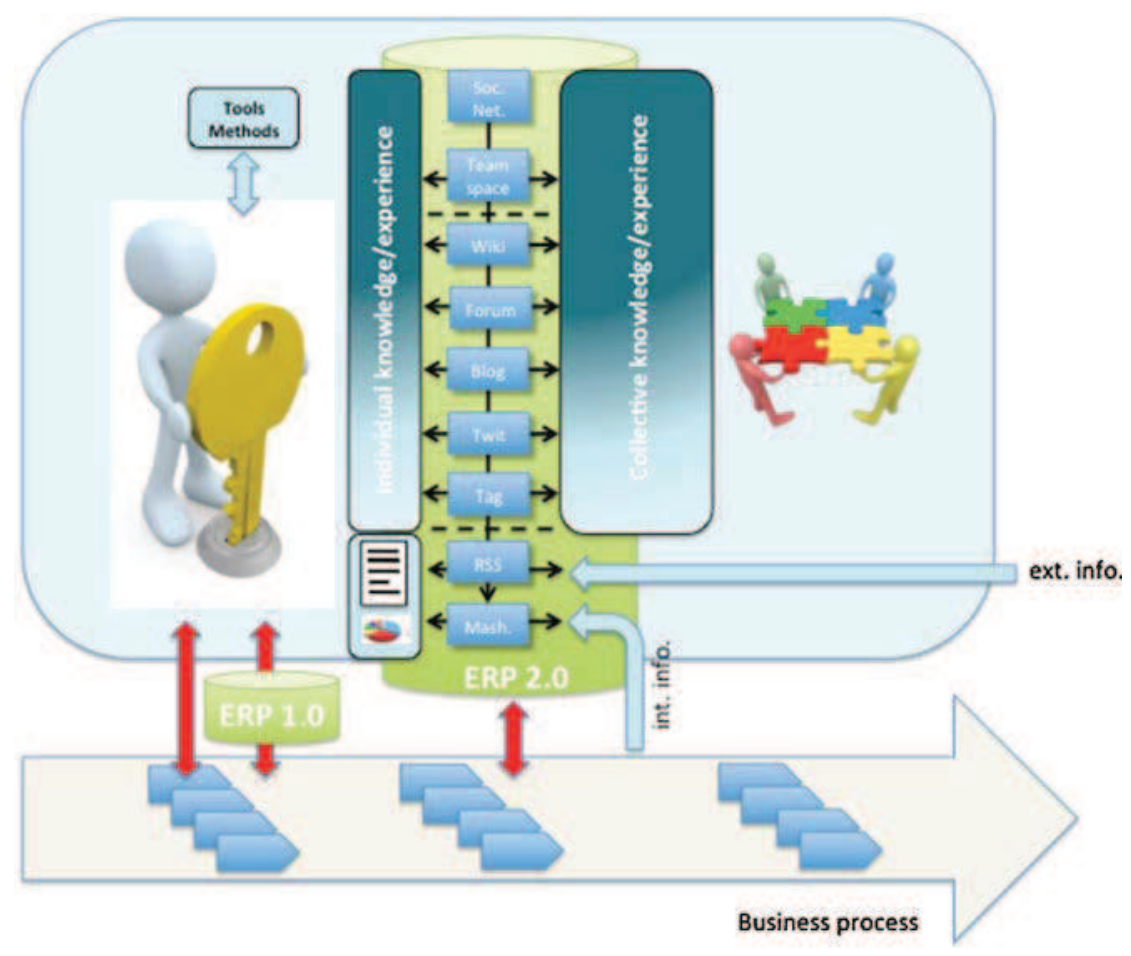

Fig. 4. The ERP 2.0.

oriented on a working group and may for instance be used for disseminating news.

- blogs are also asynchronous one-directional communication means, but can be more comprehensive than tweets (possibly including images or videos). They are oriented on middle term communication, for instance for disseminating opinions.

- a forum is an asynchronous but multi-directional communication mean, usually dedicated to middle term information but allowing direct exchanges, which are not the main objectives of tweets and blogs (even if comments may be made on blogs). As already mentioned, "instant messaging" can be considered as a synchronous forum.

- a wiki is quite different since it is supposed to formalize long term information/knowledge, by asynchronous exchanges between actors.

- workspaces allow a synchronous (using tools such as video conferencing, instant messaging) or asynchronous (since they also include forums, wikis or other tools) communication. If included in the ERP, they should allow a full access to all the information stored in the ERP.

- finally, social networks should play in the ERP 2.0 a quite different role: they should be used to build communities according to various objectives or criteria, within which the previously described tools could be used. They can for instance be used for applications such as gathering employees involved in the same project or gathering the customers of the company.

Few ERPs have at the moment publicized on the term "2.0". Some of them seem to assimilate "2.0" and the fact that they are accessible as a service (SaaS), sometimes using a web browser. Others already include several 2.0 facilities: in next sections, the example of the new version of "Business By Design", an ERP edited by SAP, is taken for giving more operational illustrations on what could be and how could be used an "ERP 2.0".
3.2. Adding 2.0 functionalities to an ERP: the example of "Business By Design"

Business By Design (ByD) ${ }^{33}$ is an ERP launched by SAP in 2007, dedicated to companies of medium size. It does not have at the moment the full industrial coverage of the best known SAP Enterprise Central Component (ECC), ${ }^{34}$ focusing on discrete manufacturing and services, but offers interesting new features:

- it is a SaaS product (Software as a Service), and is used through an Internet navigator. Therefore, it does not have to be installed in the company, and is maintained by the editor,

- it is "user oriented": it includes tools allowing the users to perform the initial transfer of the companies' data and to parametrize the system in the implementation phase (including the customization of the screens),

- it includes several additional tools providing functionalities of the Web 2.0. Nevertheless, it will be shown hereafter that there is no standard integration of these tools in the business processes: this has to be done by consultants or by the user himself. Therefore, ByD can be considered as being "potentially" an ERP 2.0 , depending on the use done of the included 2.0 tools.

The following tools are available in the version 3.5 of Business By Design ${ }^{35}$ :

- RSS: ByD gives to the users the possibility to use RSS feeds for having access to external information on their workstation, this information coming either from inside or outside the company. - MashUps: mashups can easily be included in ByD via intuitive drag-and-drop, with the help of the built-in "Data Mashup Builder" allowing data source configuration and live result

\footnotetext{
33 http://www.sap.com/pc/tech/cloud/software/business-management-bydesign/overview/index.html.

${ }^{34}$ http://www.sap.com/pc/bp/erp.html.

35 http://scn.sap.com/community/business-bydesign/blog/2012/01/30/biggestenhancements-in-feature-pack-35-of-sap-business-bydesign.
} 


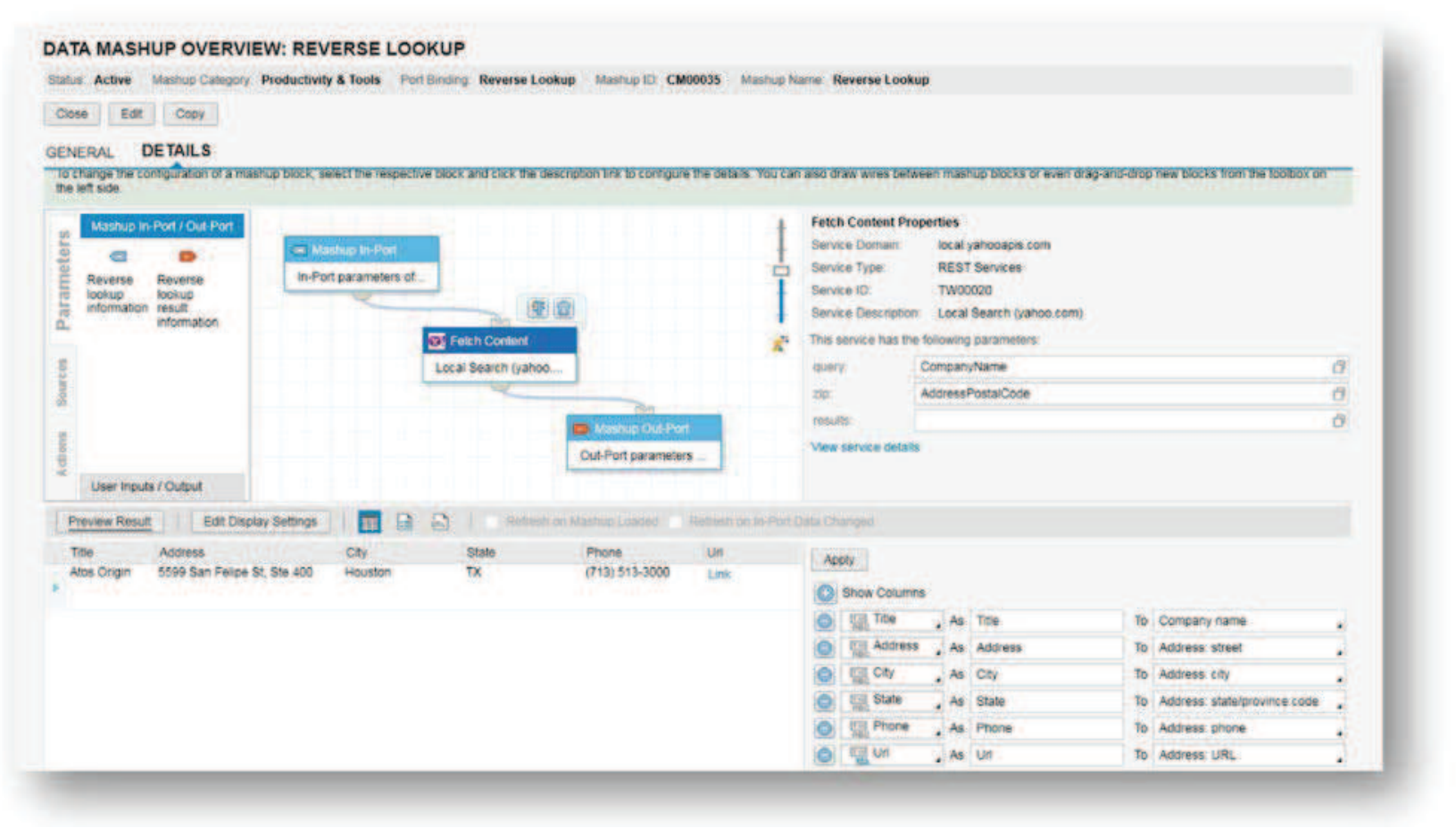

Fig. 5. Integration of a mashup in ByD.

preview (see Fig. 5). Pre-configured mashups are available in the standard version of ByD, since the exchange of data between emitting and receiving applications has already been done. These pre-configured mashups include communications with Google Map, Bing, Route planners (Google and Bing), Search for a person (using Twitter or Facebook), and Search for company (using Twitter).

- Visualization of the available information: a web-like interface allows the users to access all the information available in the company's database and to create their own analysis without requiring a specialist.

- Tagging and bookmarking: users may assign tags to each object present in the system (customer, materials, customer order, etc.). When selecting a tag, the user can view the different objects that have been tagged. Depending of their access right, other users will be able to access the tagged object via hyperlinks. Users can also flag different objects or add them to "favourites". They will then be able to access these object directly from their "flag and favourite" overview.

- Web services: ByD can give access to external web services, like Online Sales Service. ${ }^{36}$ The two applications can be linked by a bidirectional link: e.g. if an order is created in a remote Online Sales Service, it is also automatically created in ByD.

- New collaboration tools: a new tool named Feed, allowing group discussions and instant messaging, is provided in $\mathrm{ByD}$, allowing the actors to perform direct exchanges of information on their ByD workstation. This tool also allows to comment the data and transactions of the ERP.

- Mobility: a set of ByD applications is available on different smartphones and tablets for providing an easy access to the system from anywhere.

- Groupware integration: a special add-on has been developed for Outlook $^{37}$ for creating a direct link between the groupware and the ERP. The following features are proposed:

36 http://www.online-sales.com/.

37 http://outlook.com.
1 Email:

a. Emails synchronized with ByD CRM as activities,

b. Contacts/accounts identified for these emails in ByD,

c. All interactive email activities can be retrieved when viewing the account.

2 Appointment:

d. Appointments synchronized with ByD CRM as activities,

e. Contact/Accounts identified for these appointments in ByD,

f. All interactive appointment activities can be retrieved when viewing the Account, Attached visit report are uploaded by the Groupware client into ByD,

3 Appointments created in ByD are synchronized with the Groupware client.

4 Any updates of the appointment in ByD are reflected in the Groupware client.

These tools may be the bases for deploying a real 2.0 ERP in the company. Nevertheless, no systematic methodology is proposed in that purpose. In order to address this problem, some guidelines summarized in next section have been suggested for identifying needs, choosing a 2.0 tool adapted to address these needs, then embed it in the ERP.

\section{Guidelines for development of 2.0 applications in an ERP}

As seen in previous sections, most of the companies nowadays think that the techniques related to the Web 2.0 are a potential source of improvements for their business processes. Nevertheless, the companies are still using an empirical "test and trials" approach and do not really know if their actions have a satisfactory ROI or even bring benefits [6]. With a special focus on the combination of 2.0 techniques and ERP systems, this section aims at giving some guidelines for a more systematic exploitation of this new paradigm in business processes. 


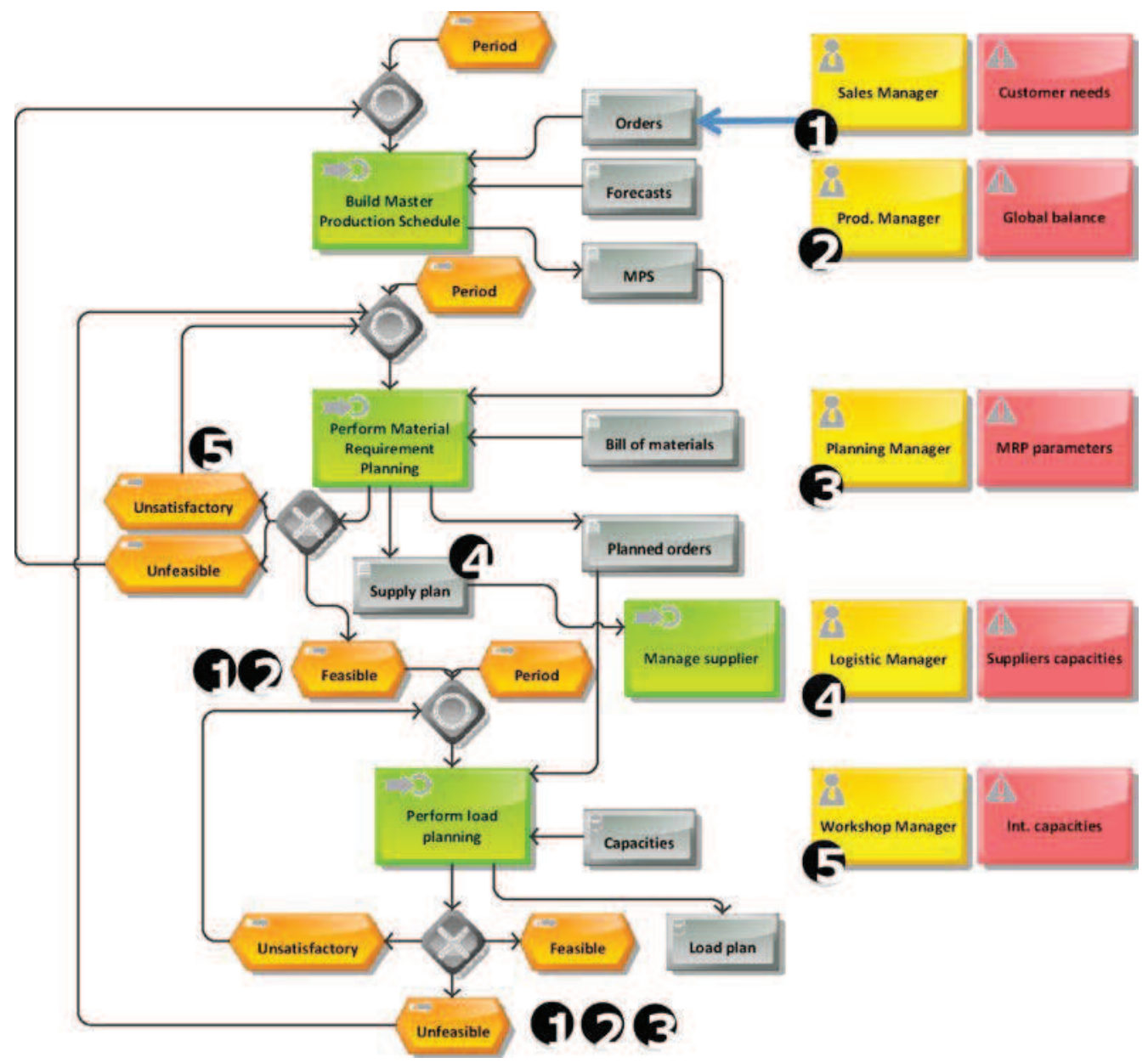

Fig. 6. Business model of a classical MRP process.

\subsection{What points to improve?}

In our opinion, a key problem of the business processes as usually modelled in the companies is their focus on the successive transformations of the main information flow by activities, which may lead to processes fragmented in a large number of poorly linked activities. Visualizing "secondary" information sources and flows can in our opinion allow to diagnose some problems. Let us take as an example the simplified process of Fig. 6 describing, using the ARIS formalism [91], the sequence of activities involved in a classical MRP industrial planning process [92].

A Master Production Schedule (MPS) is first built on the base of forecasts and already received orders, then the Material Requirement Planning (MRP) step calculates the materials required for producing the final products. The result is on one side a supply plan (for the components bought from external suppliers) and on the other side a set of internal planned orders (gathered in a production plan). On the base of the routings, these sequenced orders allow to build the load plan. We have visualized in Fig. 6 the loops which are often necessary before obtaining a satisfactory plan: if the MPS, supply plan or production plan are not satisfactory, they can be modified by the activities which have produced them. Nevertheless, if the decision makers consider that their available degrees of freedom are not sufficient for making them acceptable, the plans are considered as "unfeasible" according to the received framework. This sets into question the upper level plan (MPS if the supply plan or production plan are unfeasible, production plan and supply plan if the load plan is unfeasible). As a consequence, many loops may be required, with the result of wastes of time and possible instability.

The origin of this (known) problem can be visualized by the right side of Fig. 6 in which the main actor of each activity is mentioned (which is classical in process modelling) together with the main knowledge that each actor uses for making is decision (which is an addition to the model).

For clarity purpose, we have denoted by numbers in the main process model where this knowledge is used: indeed, this knowledge is not only required for creating information (here: plans) but also to assess the feasibility of other decisions. For instance, the supply plan is usually not built by the Logistic Manager, but his knowledge on the possible extra-capacity of the suppliers is required to assess the feasibility of this plan. Several similar examples are denoted in Fig. 6.

Unfortunately, the feasibility of the plans cannot be checked (even roughly) at the upper level, since the MPS concerns a given product, whereas the capacities of the suppliers and internal workshop depend on all the products respectively bought at a given supplier and produced by a given workshop. Therefore, the information allowing to check the feasibility of the plans is not present at the MPS level.

In industrial applications, this problem has been solved by introducing an upper level to the planning process: a so-called "Sales and Operation Planning" (S\&OP) activity is now often performed before the MPS, considering groups of products in order to have a global view of the required load and available 
capacity. It is a collaborative activity, involving all the actors listed in the right part of Fig. 6; therefore, all the sources of knowledge may be used in order to get a rough "feasible" global planning. The S\&OP allows then to create one MPS for each product of the group. This new step usually allows to obtain feasible plans at all the following levels.

We see that in the MRP field, a problem of fragmentation of knowledge has been empirically addressed by creating a collaborative activity aiming at giving consistence to "local" decisions. We suggest to generalize this specific example by the following additions to the classical Business Process Models:

- add to the "primary" information flow, consisting in structured data already managed by the ERP, which is the main object of the process, a "secondary" information/knowledge flow concerning for instance contextual information or criteria of acceptance. A good way to distinguish between primary and secondary information flow is that the secondary flow is not transformed. It is not required for finding a "feasible" solution, but very useful for finding a "good", "shared" one. For instance, the production plan is necessary to perform a load plan, but not the capacity of the machines. The primary information flow is usually managed through the ERP whereas the secondary information has often to be provided by external means (see Fig. 3).

- list the actors who perform the activities (this is classical but not systematically done), but also those who may validate or influence the documents created in the process,

- if necessary, mention the roles of the actors in the concerned step of information processing (create, influence, modify, validate, etc.) (see [90]),

- mention explicitly the type of knowledge/information that the actors use to perform their role. All primary and secondary information should at this step be linked to an actor.

This "extended model" (including secondary information flow, close actors and roles), which may be simplified in given cases, may allow to perform a first diagnosis concerning the enrolment of the actors in the process and the way information/knowledge is accessed/dispatched, through questions like the followings:

- can "loops" be detected in the process linked to sequences of production, validation and modification of documents and information? This point could bring to re-design the process using collaborative activities.

- can the process model be simplified by the distribution of some centralized activities aiming at coordinating actors/activities of the process? This point should lead to the creation of secondary information flows between activities/actors allowing a decentralized coordination.

- can the process be improved by facilitating the access/ interpretation to internal or external sources of information/ knowledge (visualization)?

- can the process be improved by providing access to new internal or external sources of information/knowledge (new information/ knowledge)?

These questions mainly aim at identifying sources of information/knowledge that would not be managed by the ERP but would be useful for improving decision making, mainly by reflecting the interests/knowledge of other decision makers. They should allow on one hand to redesign the process with a better orientation on information/knowledge sharing and collaborative work (involving mainly collaborative workplaces and social networks) and on the other hand to facilitate the access to information and knowledge using other 2.0 tools.
Once the points of improvements have been identified, the question is to choose the best 2.0 tools for performing these improvements.

\subsection{With which tools?}

We have shown in Table 1 (Section 2.2.7) the main characteristics of the 2.0 tools regarding the type of communication that they allow (mono-directional, bi-directional), the synchronicity between actors, the dynamicity (frequency of update) and other properties. Once the needs for a better management of information/knowledge have been identified using the extended process model suggested in Section 4.1, a classification of the tools like the basic one suggested in Table 1 may help to choose an appropriate tool. This will be shown with more details in the case studies (Section 5).

Using the basic steps presented in Sections 4.1 and 4.2, we suggest in next section two (loose) methodologies respectively dedicated to the improvement of an existing process and to the development of a radically new one.

\subsection{Methodology}

The objective is to have a consistent (even if flexible) methodology for passing from an identified problem to a solution using 2.0 tools (if it may be of interest), in order to increase the chance to choose the right approach and the right tool for addressing the problem.

Two main ways to introduce the Web 2.0 tools in business processes can be considered, summarized in Fig. 7. Broadly speaking, method 7.a describes an improvement of existing processes using Web 2.0 tools (like in Channellock Inc. [42], WindRiver [44], FONA [55], Emerson [57] in Section 2). In that case, activities and processes are considered as pre-existing and the process models are completed with actors, secondary information and knowledge, as suggested in Section 4.1. The activities can be improved by 2.0 tools, but the process can hardly take benefit of the full potential of these tools. As suggested by [90] for designing collaborative business activities, the business processes could be more drastically improved if set into question and re-designed around 2.0 tools. In Fig. 7b is suggested in that purpose the following step-by-step (but flexible) methodology:

1. Choose the main target in the ERP context (situation/process)

A situation or process that does not give satisfaction is identified and roughly modelled, emphasizing the problem to solve.

2. List the stakeholders involved in the process

The main actors (internal or external) involved in the process are explicitly identified (for instance: customers and employees for a problem in the Sales and Distribution area; logisticians and suppliers in the "Logistic" function).

3. Model the process or exchanges of information between the concerned Stakeholders ("as-is")

The goal is here to describe the existing process (as-is" model). The choice of a tool will depend on the nature of the process:

- if the considered process mainly consists in exchanges of information, a simple tool like the UML sequence diagram [93] may be sufficient (see Section 5.1),

- if the process mainly involves information processing activities, a more comprehensive process model may be required (see Section 4.1 in which the ARIS model is used).

4. Choose of the 2.0 tools for implementing these exchanges 


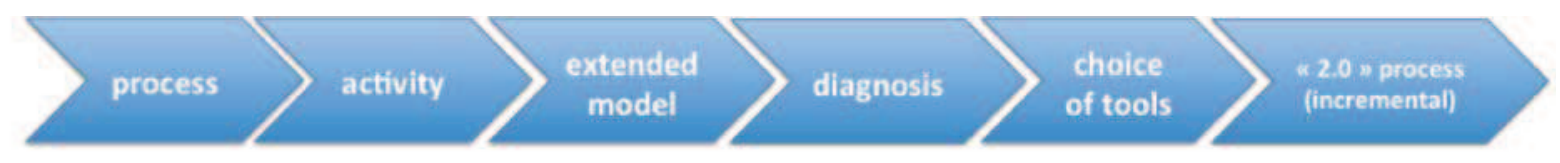

a. " 2.0 " tools in the improvement of existing processes

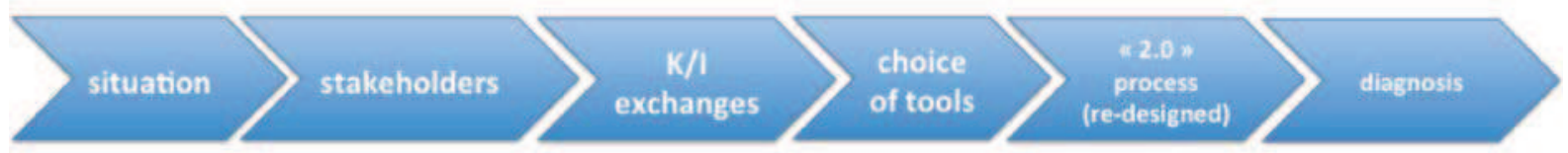

\section{b. " 2.0 " tools as a mean for process reengineering}

Fig. 7. Introduction of 2.0 tools in Business Processes.

The characteristics of the information exchanges identified in previous section are compared to the characteristics listed in Table 1, allowing to guide the choice of one or several 2.0 tools. This choice is made according to the requirements expressed in step 3, but also to the cost and easiness of their implementation.

5. Model the business processes around the use of the 2.0 application ("to-be").

The development of the 2.0 application should allow to precisely reformulate the concerned business process/ exchanges of information (see Fig. 7).

6. Analyze the obtained process using diagnosis rules.

If problems are still detected, come back to points 5 or 4 .

This step-by-step methodology is of course only a loose framework, which can be simplified in given applications, as shown in the first tests of this approach on real implementations of Business By Design described in next section.

\section{Tests on real cases}

The companies considered in these real case studies were already using an ERP. The reason of their interest for 2.0 tools was that customizing the ERP for addressing the identified problems was considered as too costly and complex. Indeed, having the objective to manage $100 \%$ of the business cases through ERP transactions is a known cause of over budget and delays. For most of ERP consultants, an ERP should manage the majority of the business cases, but not all of them, since the system is not flexible enough to be adapted to specific development at low cost [76]. The part of the business cases managed by the ERP is often called the "baseline". The baseline management represents the majority of the working time of a user, but there are always non-standard activities that have to be managed outside the ERP, often using collaboration and external tools. The challenge is to be sure that these activities communicate adequately with the ERP.

The interest of the considered companies for using 2.0 tools was therefore to manage non-standard activities via ERP-embedded collaborative tools, instead of using the ERP processes themselves. Four positive impacts were expected:

- the standard baseline process would be kept easy to use,

- the management of the non-standard activities would be facilitated by the information available in the ERP,

- information that would have been managed outside the ERP would be sent back to the ERP,

- all information exchange would be centralized in the ERP. In that way, all exchanges would benefit from the ERP added value.
This answers to two of the most important issue of the companies: improve the data quality and improve the involvement of the user in the information system.

\subsection{Introductive examples}

\subsubsection{Sales and delivery process}

For a validation on a simple experiment, the sales and delivery process of several companies was firstly considered (step 1 of the methodology described in Section 4.3. Since this process involves external partners, the actors of a company often need external information for performing the process. The possible interest of 2.0 tools was tested in that purpose.

"As-Is" process: the main stakeholders were identified as the company, the customers and the carriers (step 2). A simplified analysis of the "as-is" process (step 3) showed that the most commonly used external sources of information were:

- geographical details on the customers, obtained from external web sites (map providers), typically for locating the customer or obtaining easily the distance between him and the nearest point of sales.

- information on the customers' business (e.g. products, markets), obtained by consulting regularly their web sites,

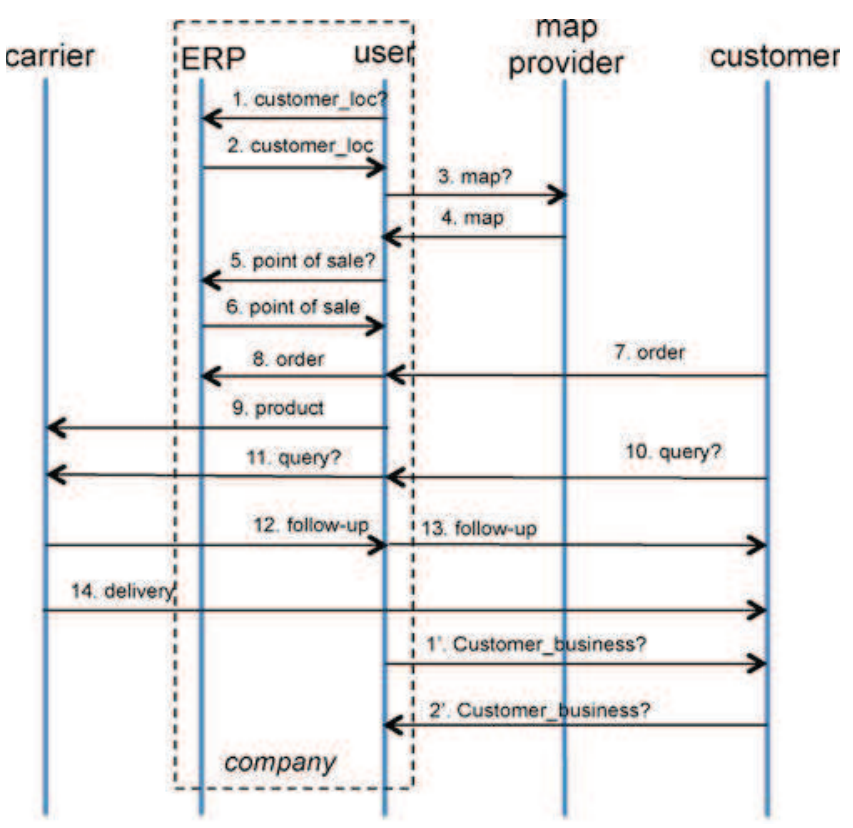

Fig. 8. Exchanges between actors, "as-is" process. 


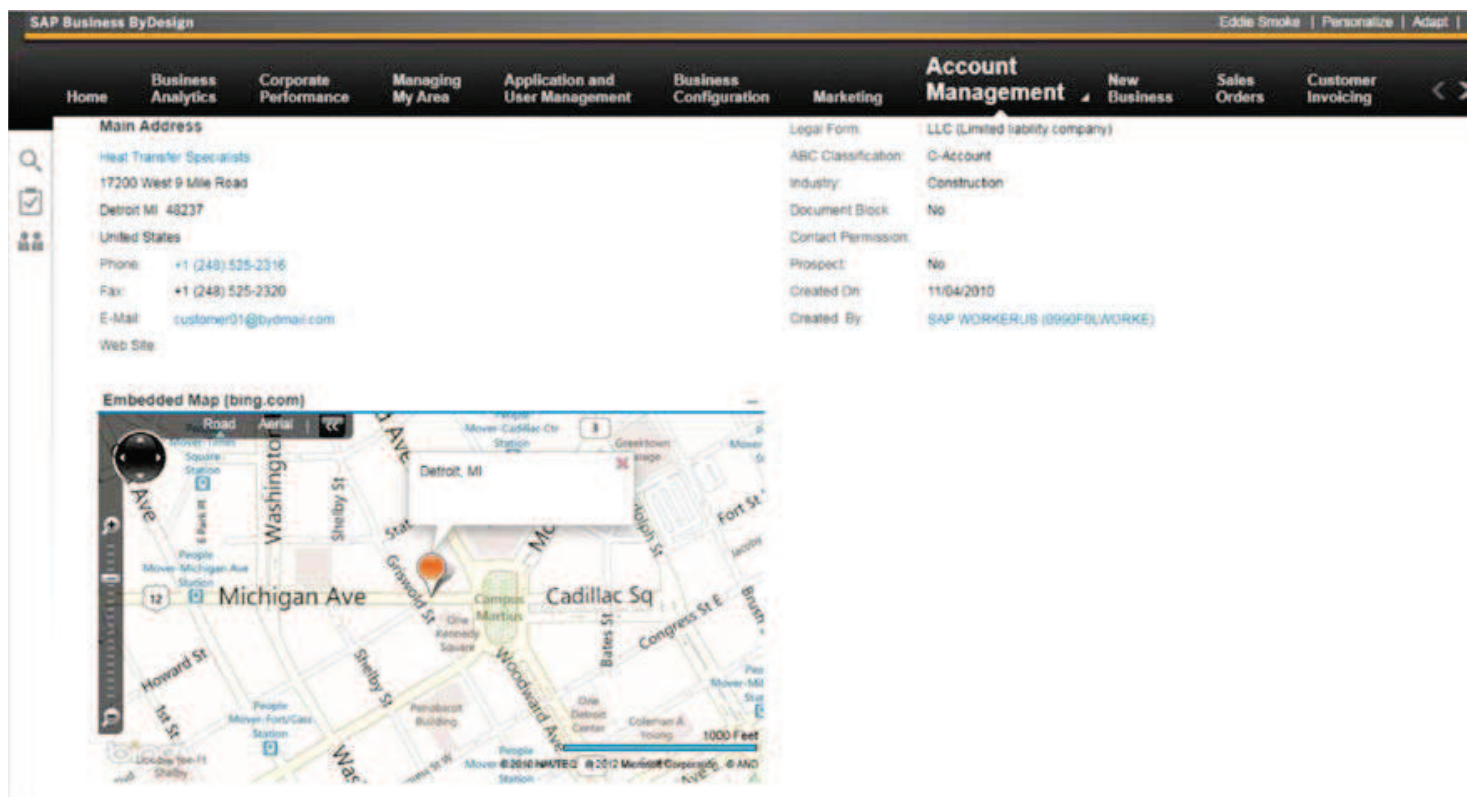

Fig. 9. Use of a mashup for geographical information on the customer.

- information on the status of ongoing deliveries, performed by external carriers and accessible through their web sites.

The exchanges of information between the actors in the "asis" process are summarized in Fig. 8, showing two main problems:

- the saturation of the user by exchanges of queries/answers with the external actors,

- the fact that, as denoted in Fig. 3, the "secondary" information flow is managed outside the ERP, and is therefore not recorded in the main information system.

Choice of 2.0 tools and "To-Be" process: If we refer to the characteristics of Table 1, these exchanges concern information, for oneself, in a synchronous way, on a recurrent base. They could therefore be performed using RSS or mashups (see Table 1 ). The final choice (step 4) was in fact simple in this case, since the information was to be provided by external sources: the form in which the information is made available by its source conditions the way information will be handled in the company. The final choices were then:

- Mashups using either Bing Map (see a standard example in Fig. 9) or Google Map for addressing the need for geographical information on the customers,

- when available, RSS feeds from the customers were included in the ERP: each time the user opens the "customer screen", RSS feeds are updated according to the selected customer and the last news published by the customer are displayed by the ERP.

- since Web services were available from most of the carriers, it was decided to subscribe to these web services using ByD. As a typical example, a connection was done with their Freight Forwarder system, in order to get precisely the status of the delivery of the orders via the ERP. The tracking ID is sent via a web service to the forwarder system. The forwarder system sends back the status of the delivery. The status is automatically updated in the ERP.

The exchanges of information in the "to-be" process are summarized in Fig. 10, showing that the ERP is now in charge of gathering/displaying information to the user, in a contextualized way, i.e. linked to entities described in the ERP (order, customer, etc.). In Fig. 8, the user emits seven messages and receives six, while in Fig. 10, four messages are emitted by the user and three are received, resulting in a load approximately divided by two.

\subsubsection{Experiment on a project management process}

A different type of need was expressed by the project management department of company A.

"As-Is" process: in company A, projects use specific technologies. Building a project team requires clear information on the actors having already knowledge on a given technology. The involved technology was then to be added to the description of a project, and the experience of each actor in a given technology was also to be recorded. The information was updated in a centralized way by the Human Resource team. A questionnaire was sent regularly to the employees in order to track changes. These changes were then introduced in the tool by a central team.

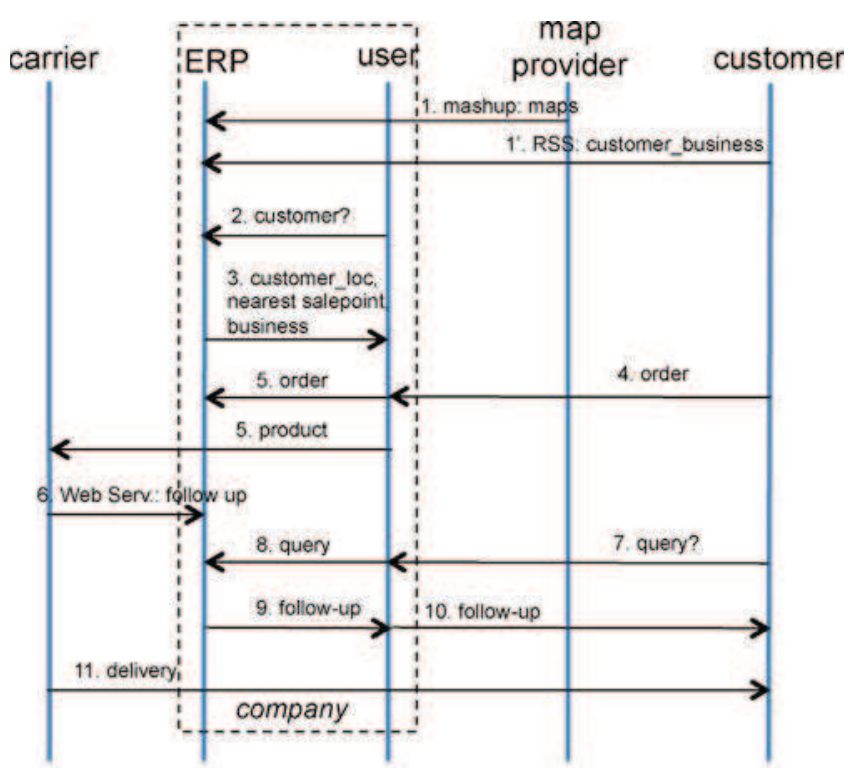

Fig. 10. Exchanges between actors, "to be" process. 


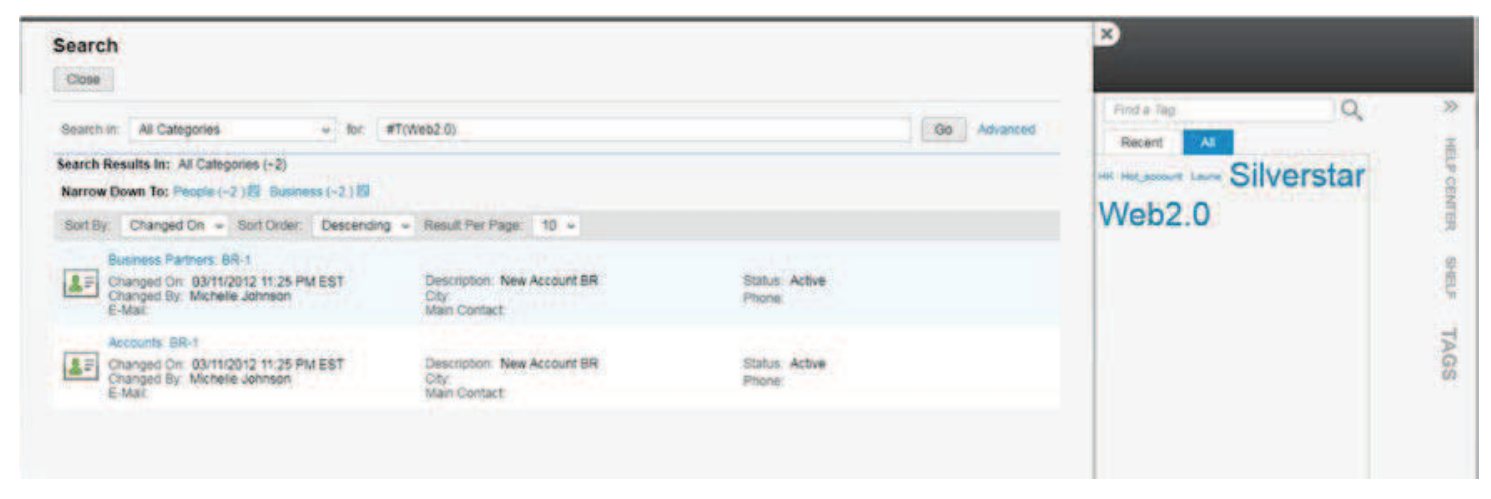

Fig. 11. Adding and retrieving complementary information to the ERP using tags.

The detected problem was of course that the data-base may never be up-to-date in comparison with actual practices.

Choice of 2.0 tools and "To-Be" process: according to the classification of Table 1 , this need concerns information, for others, asynchronous, recurrent, at middle or long term. This suggests tags or blogs as candidate tools. Since the information is attached to an object of the information system (project) and not to a person, it was decided that the easiest solution was to add the involved technology to the project description using a tag (step 4, see Table 1). It becomes then immediately possible to search the ERP database according to these tags (the search engine dedicated to tags in ByD is shown in Fig. 11). Each employee maintains his own key words (tags) in the system. People can also endorse others, by adding them key words. There is no central entity for managing the key words, but the update appeared after some weeks to be much more effective than in the previous centralized process.

\subsection{The sales process in company $X$}

Company $\mathrm{X}$ sells technological components to industrial customers according to a sales process, which is the main object of the case study. Two sub-processes of the sales management process are considered:

- at long term: the dissemination of synthetic information on the customers within the sales department, in order to identify possible needs of some regular customers,

- at short term: a sales process, which may result from the previous one or from an initiative from a customer.

\subsection{1. "As-is" processes}

5.2.1.1. Identification of potential sales. Each Account Manager has an annual meeting with the Sale Manager for summarizing his activity for each customer. After this meeting, he writes a report, logs on to the information system, creates an activity linked to the customer master record and stores the report in this activity. This report should be sent to:

- the Sales Manager,

- a member of the Quality team,

- the Area Manager (responsible of the sales on a given geographical area).

In that purpose, the Account Manager looks for the names of these persons in the Customer Master Record and sends them the report by email.

The Sale Manager may ask for additional information, e.g. which new product could be sold to the customer or with which version.
In that purpose, he usually sends an email to all the actors. The Account Manager sends back the required details to all the recipients.

The advantages of this process are mainly that:

- the management of the Master data, centralizing the information, allows to use the system as a contextual directory of the persons involved in the account. Management rules allow then to define who should be contacted.

- the report (a non-structured data) is contextualized by associating it to an "activity" linked to a customer.

Nevertheless, this process has important drawbacks:

- the process of information management is decoupled from the process of information sharing: as soon as the report has been sent, all information exchanges are done outside the information system, usually by email.

- in order to be sure that the right persons receive the information without creating too complex management rules, the procedures are often oriented on a large dissemination. The consequence is a constantly increasing number of emails within the company, the "added value" emails being drown in a "cloud" of poorly significant ones. Quantity of information exchange is privileged with regard to quality.

5.2.1.2. Short term sale process.. Each sale is performed according to a macro-process containing four main activities (see Fig. 12):

- Definition of requirements,

- Analysis of the customer's needs,

- Submission of tenders,

- Conclusion of the contract.

The main actors of the process are:

- the Account Manager, who has a global view on the activities of his customers, of the sales already concluded and on the ongoing negotiations. He initializes a sale and is its main manager.

- the Sales Engineer, who is the technical support of the Account Manager during the discussions with the customer. He is the interface with the development teams.

- the Commercial Manager: his role is mainly to control and validate.

- the Customer.

Because of the specificity of the technologies involved, it often happens that the customer asks for references linked to previous 


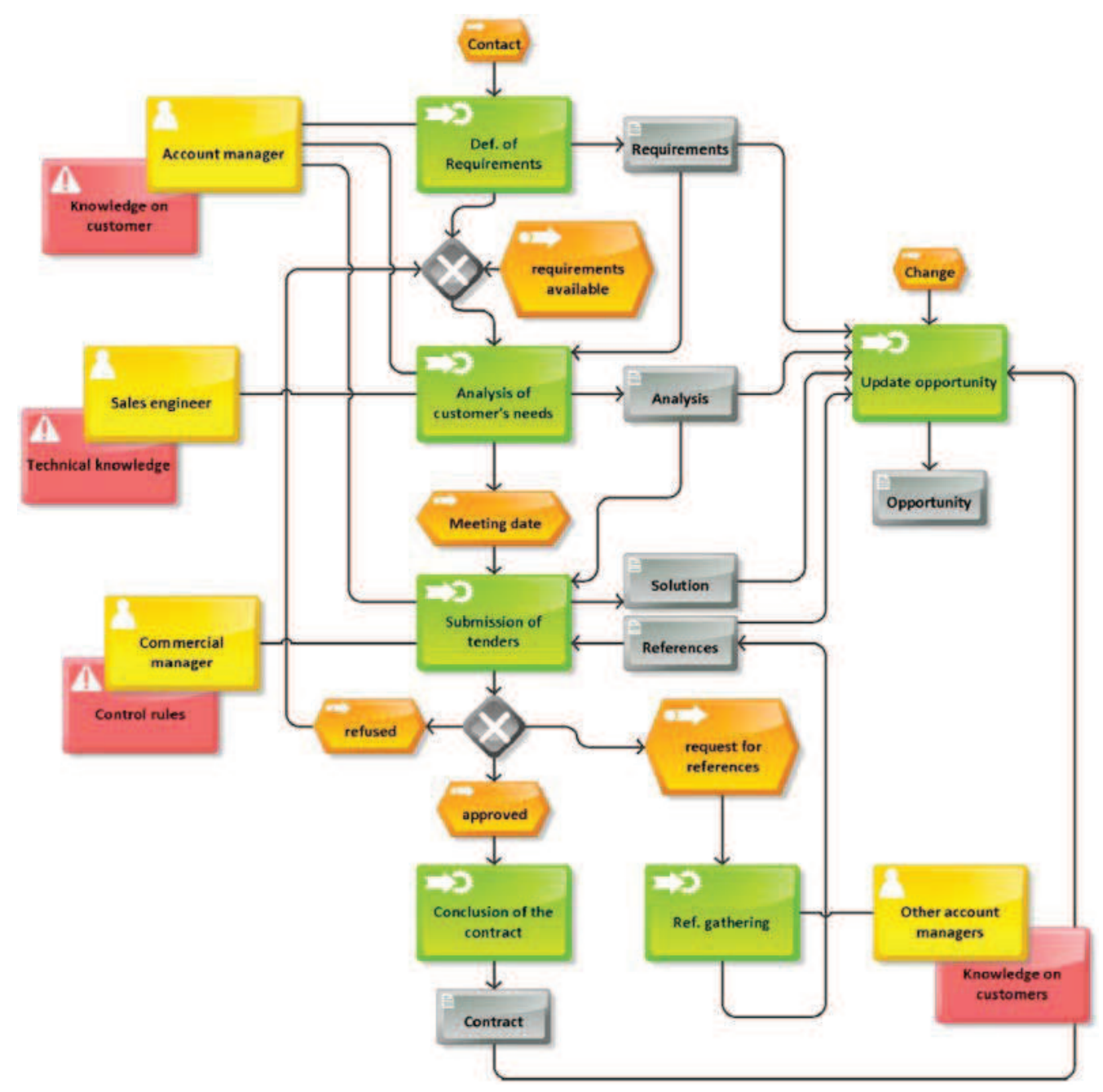

Fig. 12. Sales process.

sales (activity "reference gathering" in Fig. 12). Previous customers may be asked to give their opinion on the product to the potential new customers.

The existing Information System of the sales department is based on the concept of "opportunity" (see Fig. 12), gathering:

- the customer and his related data (e.g. address, contact),

- the status of the opportunity: in progress, won, lost,

- if it is in progress: the on-going activity, the estimated probability of success, the possible date of sale, etc.,

- if it is won, the sold articles and their characteristics (size, weight, variants, etc.),

- the actors of the sales department involved in the sale cycle (Account Manager, Sales Engineer, Commercial Manager, Development Team, etc.),

- the description of the events linked to the sale (e.g. meetings with the customer, signature of the contract).

Several problems were detected in the process of Fig. 12, among which:

- the Account Manager is the only bridge between the activities of the process. The other actors are only involved in isolation even if their decisions may depend one on another (see the interaction between the Commercial Manager, who validates the tender, and the Sales Engineer, who interprets the customer's needs),

- using the existing system, gathering references was difficult, since the Account Manager was supposed:

- to extract from the database all the "opportunities" referring to the same product,

- to contact one by one the corresponding Account Managers for knowing whether their previous customer would be ready to testify,

- to process the answers, usually made by email.

The advantage of the existing system was that the centralisation of the information in the "opportunity" allowed to find the person in charge of each previous sale. The drawback was the time taken to access the information (it is necessary to define a list of persons to contact, then to send them the request for information).

\subsubsection{Choice of 2.0 tools and "to-be" processes}

The main problem identified in the described "as-is" processes is that information is fragmented in many sources. Indeed, several activities of the two described processes aim at (1) identifying sources of information, (2) sending them queries, (3) asking for validation of the decisions made on the base of the collected information. 


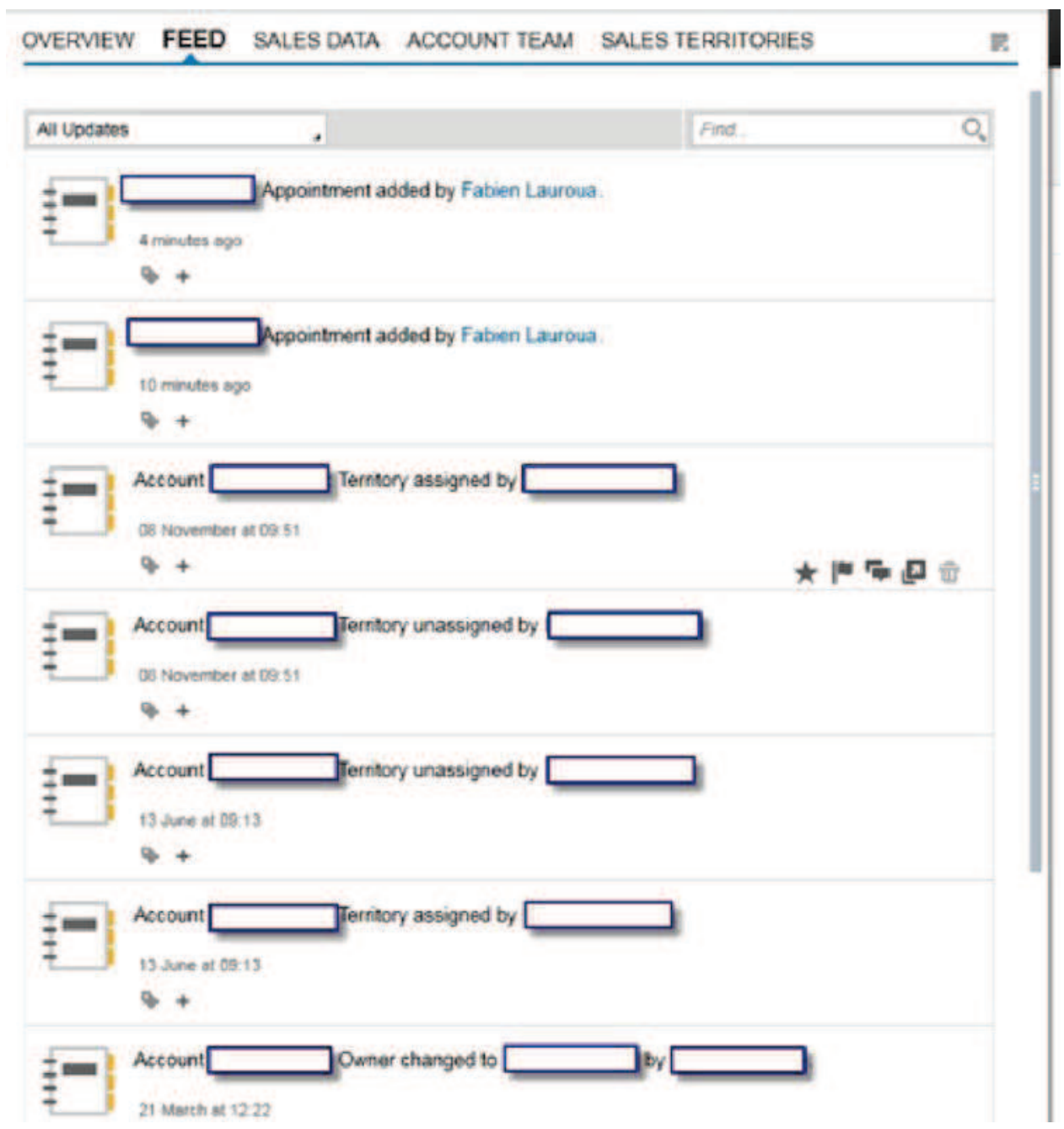

Fig. 13. Feed list.

After a preliminary analysis of the possible combinations of 2.0 tools for solving the problem, a distinction between two different needs was introduced.

On one hand, the group of actors involved in each situation of a given process is not easily identified. Since communication within the group concerns exchange of information and knowledge, in a synchronous or asynchronous way, at short, middle or long term, team spaces or social networks could be considered (Table 1). Social networks functionalities, allowing to build a formal group according to common interests, were therefore defined as the backbone of the new system.

On the other hand, once a group is built (for instance, gathering people interested in a customer or a product), exchanges between members of the group should be easy, and should be recorded in the ERP. These asynchronous exchanges concern information or knowledge, recurrently or as single shots, on short/middle term. Forums, blogs, tweets or tags could be considered in that purpose (see Table 1).

The choice was made on the Feed tool of ByD (see Section 3.2) for building the groups of users. This tool combines social network, tweets and tag functionalities; it uses Twitter codes (“@” to mention a customer or an employee, "“*” to send private update) for commenting in an opportunistic way the data and transactions of the system, whereas tags (beginning by "\#") are more dedicated to a middle/long term use. Inside Feed, groups are built as associations of users on specific subjects, defined by a label or key-word. They may concern domains of activities but also domains of expertise: the first category allow users to access information related to their activity, the second to offer services. The goal is to be able to find a group of interlocutors in each situation.

The main interests of this choice are:

- the possibility for the users to choose the "objects" they would like to "follow" (data, persons, etc.) by joining a group,

- the possibility to communicate with their internal professional network inside the ERP, communication being linked to ERP "objects" (sales, opportunity, customer, product, etc.),

- the possibility to be contextually alerted on the updates on the "objects" they follow (customers, opportunities, etc.).

Using these principles the following "to-be" processes have been defined:

5.2.2.1. Identification of potential sales.. The system gives the possibility to follow each object in the corresponding screen/ transaction. The various users are therefore invited to subscribe to the Customer Master Records they would like to follow. Opportunities, customers, employees, can be followed directly from their dedicated screen. The new process is defined as follows:

- the Account Manager writes his report after his annual meeting with the Sale Manager,

- the Account Manager creates an activity linked to the Customer Master Record and stores the report in the activity, 


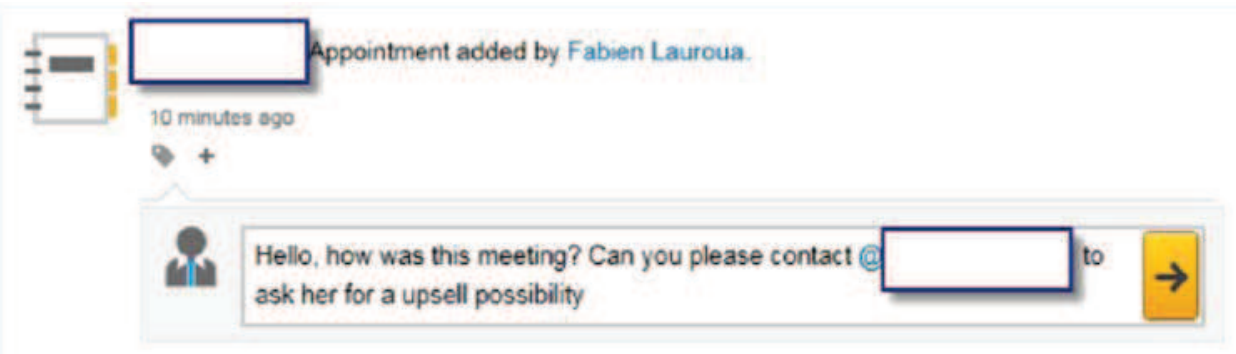

Fig. 14. Comments in a feed.

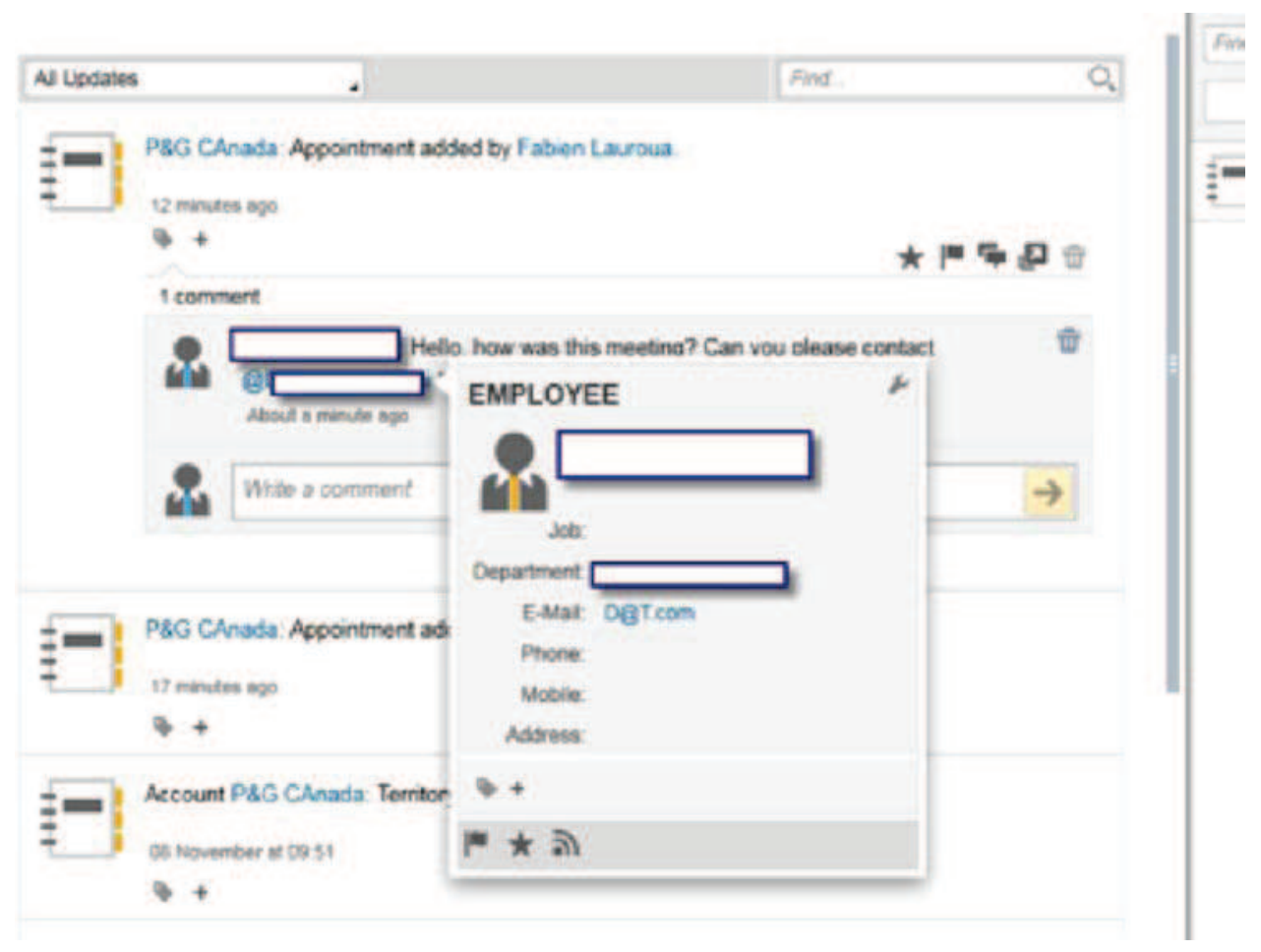

Fig. 15. Search for contact information.

- the systems automatically creates a "feed" informing the followers of the customer that a report has been added (Fig. 13),

- the Sale Manager, Area Manager and Quality Manager who subscribed to the Customer Master Data receive the information that the report has been added (through ByD, a mobile application, or through the Outlook connector ${ }^{38}$ ), so that a link to download it,

- the Sale or Area Manager can comment this feed, and ask for details (Fig. 14),

- the Account Manager answers within the feed (Figs. 15 and 16).

The advantages are:

- that the management rule that previously allowed to "push" the information to the right persons is replaced by a "pulled" information flow. The potential users register to a given information flow.

- information may be sent to the users by various channels (information system, mobile app., Outlook) but the exchanges are done inside the Customer Master Data and are recorded in the system. The information system has captured informal

http://office.microsoft.com/en-us/outlook-help/microsoft-office-outlook-hotmail-connector-overview-HA010222518.aspx. exchanges (i.e. exchanges with no specific format, that were not recorder by the previous system) and has given them a contextual value.

5.2.2.2. Sort term sales process. The entire sale process is based on the concept of group. Each participant joins groups related to the customers, opportunities and products and is automatically informed of any change on the entities he follows. The Account Manager is still the main actor of the activities of the process, but as members of the group "opportunity", the Sales Engineer and Commercial Manager may act on the produced documents in a collaborative manner within the created Feed activity.

Looking for references is considerably simplified: the account manager considers an opportunity, then posts a comment to the group "Account Manager": "which customer would accept to give testimony on product @product_X?”, @product_X being a tag managed by the system.

- the Sale Manager registered to the group “@product_X” receives the feed on their mobile app.

- if a Sale Manager answers, the Account Manager registers him in his "followers" in order to be able to follow his activities and comments. 


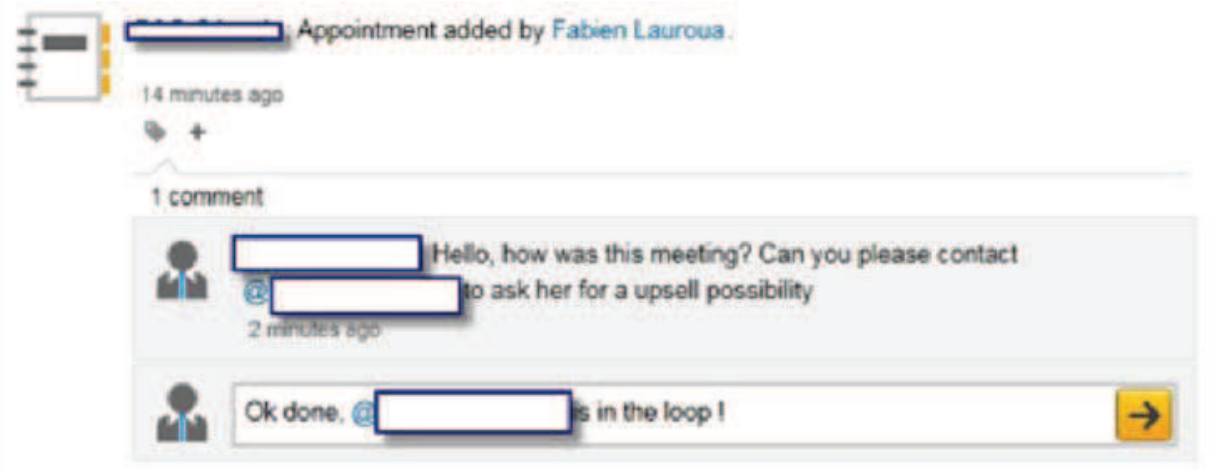

Fig. 16. Answer to comment.

The search for disseminated information held by human actors is indeed a strength of social networks. In our example, a collaborative process overrides the classical search process centred on the information system. This informal exchange is contextualized since its origin is an object of the information system: the opportunity. It is therefore clearly linked to the ERP processes.

Additionally, the use of a tag for looking for the required information allows to create a semantic reporting through a "Tag cloud" (see Fig. 2). This allows to anticipate tendencies that are not yet detected by the information system, since classical query activities performed within the information system are not recorded nor analyzed.

\subsection{Lessons learnt}

The described examples show the possible synergy between an information system (ERP) and collaborative tools (2.0 tools), first of all concerning information sharing and workflows:

- complex management rules can be avoided by giving the responsibility of receiving information to the users, who can themselves define their "level of vigilance" by deciding who and what they will "follow". Information sharing is in that way better targeted.

- communication is done using other channels than emails (mobile devices, ERP, etc.). The workload allocated to the management of the emails is decreased instead of being constantly increased as usually.

- since the information system becomes a communication channel, it captures informal flows. These informal flows benefit from this situation since they can be contextualized by the data stored in the information system (opportunity, customer, product, etc.).

The search for disseminated information is also a field in which the synergy between information system and collaborative tools may be important:

- the collaborative tools allow to access information using the collective knowledge, instead of making more complex the information system. For instance, it is clear in the previous example that a field "is reference" could have been added to the customer master data if many queries for testimony were made. Access to collective knowledge allows an immediate and much more flexible answer.

- the use of key words as tags or labels allows to follow new trends and movements, not yet perceived by a standard information system.
As an answer to [89], we do think that a synergy between information system and 2.0 tools is now possible, the information system allowing to contextualize and structure the collaborative tools by capturing informal information flows, while the collaborative tools give some flexibility to the ERP processes, making possible to access information through the information system even if it is not stored in it.

\section{Conclusion}

Pushed by their outstanding success in private uses, 2.0 tools, and especially social networks, are nowadays "fashion" tools the utilization of which gives a high-tech image to the companies. "Minimal" implementations, often highly publicized (see [61]), are certainly a consequence of this "high-tech" image. Nevertheless, several interesting applications have shown that these tools have a real potential for improving business processes, especially those related to coproduction of information or knowledge, which is a critical issue for the companies. In order to maximize the impact of these tools, it is therefore important to integrate them in the existing information system of the companies: the ERP. In that purpose, ERP editors begin to include 2.0 functionalities in their products, but a clear methodology for the definition of 2.0 business processes, supported by the ERP, is still missing.

On the base of real applications using the new version of the SAP ERP "Business by Design", we have suggested in this article the first guidelines of a methodology aiming at facilitating the identification of points to improve using 2.0 tools, then at choosing and implementing the right tool. The first tests have in our opinion shown the interest of such methodology, but also the necessity to adapt the method to each case: the way the existing processes are modelled should for instance be adapted to each situation (e.g. there is no need of complex process models for the simple examples shown in Sections 5.1-5.3). We have suggested here UML diagram models for simple cases and an extended ARIS model for complex ones, but other tools could be of interest.

New developments are now in progress in order to improve these first guidelines, especially in four main directions:

- even if standard tools have been used until now for process description, a dedicated tool could perhaps be of interest for a more communication-oriented description of the process, allowing for instance a better categorization of various types of collective work, or a better distinction of what is done inside and outside the ERP;

- in relation with the description tool, major developments should be done on the production of rules allowing to diagnose problems 
linked to exchanges of information/knowledge that could be solved by 2.0 tools. Such rules could be close to the "diagnosis rules" suggested by the GRAI method in the field of Production Management [84];

- the characteristics of the 2.0 tools should be refined, and these characteristics should be better coupled with the diagnosis rules for allowing an easier choice of the best 2.0 tools in a given situation;

- the social implications of the adoption of new information/ knowledge sharing tools will be now more specifically analyzed and integrated in the methodology.

The issue behind this research is the definition of real 2.0 organizations, allowing relationships between people to be better supported by the ERP, the business processes being completely restructured around concepts like team working, personal involvement, knowledge sharing and distributed decision making.

\section{Acknowledgments}

B. Grabot, A. Mayère and R. Houe would like to thank the partners of the SyGeo Project (MLState, HEC, Scan \& Target), and especially L. Sliman, for their help.

All the authors would like to thank their anonymous reviewers for their thorough analysis and constructive remarks for improving this article.

\section{References $^{39}$}

[1] A. Mayère, I. Bazet, ERP implementation: the question of global control versus local efficiency, in: B. Grabot, A. Mayère, I. Bazet (Eds.), ERP Systems and Organisational Change, Springers Series in Advanced Manufacturing, Springer, London, 2008.

[2] L. Stapelton, Modes of reasoning in theories of the social impact of advanced technology: a critique of ERP systems in healthcare, Annual Reviews in Control 30 (2) (2006) 243-253.

[3] B. Light, A. Papazafeiropoulou, Contradictions and the appropriation of ERP packages, in: B. Grabot, A. Mayère, I. Bazet (Eds.), ERP Systems and Organisational Change, Springers Series in Advanced Manufacturing, Springer, London, 2008.

[4] J.R. Taylor, S. Virgili, Why ERPs disappoint: the importance of getting the right organisational text right, in: B. Grabot, A. Mayère, I. Bazet (Eds.), ERP Systems and Organisational Change, Springers Series in Advanced Manufacturing, Springer, London, 2008.

[5] A.M. Kaplan, M. Haenlein, Users of the world, unite! The challenges and opportunities of Social Media, Business Horizons 53 (1) (2010) 59-68.

[6] ChessMedia, State of Enterprise 2.0 Collaboration, Q2, 2011.

[7] T. O’Reilly, Web 2.0. Principles and Best Practices, O' Reilly Radar, 2006.

[8] T. O'Reilly, What Is Web 2.0: Design Patterns and Business Models for the Next Generation of Software, 2007, http://mpra.ub.uni-muenchen.de/4580/ (accessed 07.12.13)

[9] P. Anderson, What is Web 2.0? Ideas, technologies and implications for education, in: Rapport JISC Technology \& Standards Watch, 2007.

[10] F. Bonnassieux, R. Harakaly, P. Primet, MapCenter: an open grid status visualization tool, in: Proceedings of ISCA 15th International Conference on parallel and distributed computing systems, Vienna, Austria, July 2-5, 2002.

[11] S.P. Borgatti, A. Mehra, D.J. Brass, G. Labianca, Network analysis in the social sciences, Science 323 (5916) (2009) 892-895.

[12] D.M. Boyd, N.B. Ellison, Social network sites: definition, history, and scholarship, Journal of Computer-Mediated Information 13 (1) (2007) 210-230.

[13] M. Wasmann, M. Spruit, Performance management within social network sites: the social network intelligence process method, Business Intelligence Research 3 (2) (2012) 49-63.

[14] J. Snell, An Overview of the Atom 1.0 Syndication Format, IBM, 2005

[15] DeveloperForce, Wiki. Mashups: The What and Why, 2011, http://wiki.developerforce.com/page/Mashups:_The_What_and_Why (accessed 07.11.13).

[16] C. Aman, The 3 Best Internet Tracking And Filtering Tools Which Help You to Reduce Information Overload, 2012, http://www.specificfeeds.com/blog/the-3best-internet-tracking-and-filtering-tools-which-help-you-to-reduce-informationoverload/ (accessed February 2014).

[17] B. Stvilia, M.B. Twidale, L. Gasser, L.C. Smith, Information quality discussions in Wikipedia. Technical Report, Florida State University, Tallahassee, 2005.

[18] L. Cych, Social networks, in: Emerging Technologies for Learning, British Educational Communications and Technology Agency (Becta), Coventry, UK, 2006.

[19] D. Millen, J. Feinberg, B. Kerr, Social bookmarking in the enterprise, Focus Social Computing (2005, November) 29-35.

39 The listed blogs can be accessed using Google.
[20] A. Fulkerson, Intranet 2.0: Collaborative Networks for the Intranet, MindTouch (2009).

[21] IBM, Documentation Center IBM Lotus Conn. 2.5, 2011

[22] S. Hardison, D. Byrd, G. Wood, T. Speed, M. Martin, S. Livingston, J. Moore, M. Kristiansen, IBM Lotus Connections 2.5: Planning and Implementing Social Software for Your Enterprise, IBM Press, 2010.

[23] Cynapse, 2013. http://cynapse.com/cyn-in/ (accessed 28.11.13).

[24] K. Baker, Feel the Pulse - Part One, 2010, http://www.novell.com/connectionmagazine/2010/01/feel_the_pulse_part_one.html (accessed 07.11.13).

[25] K. Adorno, Novell Unveils Real-Time Collaboration Platform for the Enterprise and Demonstrates Google Wave Interoperability, Novell Inc., 2009, http://www. novell.com/news/press/2009/11/novell-unveils-real-time-collaboration-platformfor-the-enterprise-and-demonstrates-google-wave-interoperability.html (accessed 07.11.13)

[26] SAP, Using SAP StreamWork (2011), http://sapstreamwork.com/ (accessed 07.11.13).

[27] Oracle, 2013. http://www.oracle.com/technetwork/middleware/beehive/overview/index.html (accessed 28.11.13).

[28] R. Hirsch, The ESME Collaboration and what it tells us about Web 2.0, 2008, https://scn.sap.com/people/richard.hirsch/blog/2008/06/23/the-esme-collaboration-and-what-it-tells-us-about-web-20 (accessed 07.11.13).

[29] Siemens, Boosting Productivity with Social Networks: Siemens Takes a Further Step Towards Enterprise 2.0, 2007, http://www.siemens.com/press/en/pressrelease/?press=/en/pressrelease/2009/siemens_it_solutions_and_services/ sis20090209.htm (accessed 07.11.13).

[30] Radiowalker, Is Mediawiki an Enterprise Wiki? 2007, http://radiowalker.wordpress.com/2007/02/16/is-mediawiki-an-enterprise-wiki/ (accessed 28.11.13).

[31] S. Ransbotham, G.C. Kane, N.H. Lurie, Network characteristics and the value of collaborative user-generated content, Marketing Science 31 (3) (2012) 387-405.

[32] A. Prasad, What Business Value Does Social Software Bring to Manufacturing? 2010, http://www.industryweek.com/articles/what_business_value_does_soci al_software_bring_to_manufacturing_23158.aspx (accessed 07.11.13).

[33] S.P. Borgatti, X. Li, On social network analysis in a supply chain context, Journal of Supply Chain Management 45 (2) (2009) 5-22.

[34] S. Wiyaja, M. Spruit, W. Scheper, J. Versendaal, Web 2.0 based webstrategies for three different types of organizations, Computers in Human Behavior 27 (4) (2011) 1399-1407.

[35] M. Treacy, F. Wiersema, Customer intimacy and other value disciplines, Harvard Business Review, Harvard, 1993.

[36] D. Godes, D. Mayzlin, Using online conversations to study word-of-mouth communication, Marketing Science 23 (4) (2004) 545-560.

[37] B.J. Jansen, M. Zhang, K. Sobel, A. Chowdury, Twitter power: tweets as electronic word of mouth, Journal of the American Society for Information Science and Technology 60 (11) (2009) 2169-2188.

[38] S. Aral, D. Walker, Creating social contagion through viral product design: a randomized trial of peer influence in networks, Management Science 57 (9) (2011) 1623-1639.

[39] L. Feng, T.C. Du, Who is talking? An ontology-based opinion leader identification framework for word-of-mouth marketing in online social blogs, Decision Support Systems 51 (1) (2011) 190-197.

[40] S. Aral, D. Walker, Identifying influential and susceptible members of social networks, Science 337 (6092) (2012) 337-341.

[41] N. Edelshain, P.W. Thorogood, Selling in the age of social media, InsideView (2013).

[42] B. Goodbaum, How Social Media Networking can Help Your Manufacturing Business, 2010, http://www.kaplansocialmedia.com/how-social-media-networking-can-help-your-manufacturing-business/ (accessed 07.11.13).

[43] D. Adebanjo, R. Michaelides, Analysis of Web 2.0 enabled e-clusters: a case study, Technovation 30 (2010) 238-248

[44] N. Doan-Huy, Y. Xu, N.R. Kondapaka, M. Wood, Building Enterprise 2.0 Applications, 2009, http://www.oracle.com/technetwork/articles/enterprise2/ building-e20-applications-101935.html (accessed 07.11.13).

[45] D.A. Lombardo, Rhobi Offers Virtual Parts Marketplace, 2010, http://www. ainonline.com/aviation-news/ainmxreports/2010-05-12/rhobi-offers-virtual-partsmarketplace (accessed 07.11.13).

[46] M. Sigala, eCRM 2.0 applications and trends: the use and perceptions of Greek tourism firms of social networks and intelligence, Computers in Human Behavior 27 (2) (2011) 655-661.

[47] D. Hinchcliffe, The Advent of the Social Supply Chain, 2010, http://dachisgroup. com/the-advent-of-the-social-supply-chain/ (accessed 07.11.13)

[48] S. Bourdier, Enjeux et apports du Web 2.0 pour la circulation de l'information dans l'entreprise: le cas du service de veille stratégique du groupe Yves Rocher, (CNAM thesis), 2007

[49] IBM, Promouvoir le Web 2.0 dans l'entreprise: comment le Directeur des Systèmes d'Information peut stimuler la croissance et obtenir davantage d'efficacité organisationnelle, January, 2009.

[50] T. Beverly, Real-world intranets in 2010: SWOT analysis, Business Information Review 27 (2) (2010) 85-93.

[51] J.B. Barnes, M. Böhringer, C. Kurze, J. Stietzel, Towards an understanding of social software: the case of Arinia, in: 43rd Hawaii Int. Conf. on System Sciences, 2010.

[52] A. Rosen, Lockheed Martin Sets Up Private Social Network, 2009, http://www.manufacturing.net/news/2009/07/lockheed-martin-sets-up-private-social-network (accessed 07.11.13).

[53] A. Passant, Case Study: Enhancement and Integration of Corporate Social Software Using the Semantic Web (EDF), 2008, http://www.w3.org/2001/sw/sweo/public/ UseCases/EDF/ (accessed 07.11.13). 
[54] M.J. Brzozowski, WaterCooler: exploring an organization through enterprise social media, in: Proceedings of the ACM 2009 international Conference on Supporting Group Work, Sanibel Island, Florida, USA, May 10-13, 2009.

[55] C. Lynch, FONA Wins a CIO 100 Award for Use of Enterprise Social Networking Software from Socialtext, 2010, http://www.socialtext.com/news/ pressrelease_2010.06.01.php (accessed 07.11.13).

[56] McKinsey, How Business are Using Web 2.0 - A MacKinsey Global Survey, The McKinsey Quarterly (2007, March).

[57] W. Iversen, Social Networking Tools Penetrate Manufacturing, Summit Publishing Company, 2010, January.

[58] S. Gherardi, Organizational Knowledge the Texture of Workplace Learning, Blackwell Publishing, Oxford, 2006.

[59] F. Carbone, J. Contreras, J.Z. Herandez, J.M. Gomez-Perez, Open innovation in an enterprise 3.0 framework: three case studies, Expert System with Applications 39 (10) (2012) 8929-8939.

[60] A. Williams, Facebook in the Factory: Manufacturers Want Social Software Too, 2009 , http://readwrite.com/2009/12/17/facebook-in-thefactory\#awesm= omwsoWvjKcwnmZ (accessed 07.11.13).

[61] H.L. Cheng, Seeking knowledge or gaining legitimacy? Role of social networks on new practice adoption by OEM suppliers, Journal of Business Research 63 (8) (2011) 824-831

[62] S. Neil, Deep Drive Collaboration: Teamwork 2.0, 2009, http://www.managingautomation.com/maonline/magazine/read/ Deep_Dive_Collaboration_Teamwork_20_241622 (accessed 07.11.13)

[63] D. Hinchcliffe, A Checkpoint on Web 2.0 in Enterprise, 2007, http://www.zdnet. $\mathrm{com} / \mathrm{blog} /$ hinchcliffe/a-checkpoint-on-web-2-0-in-the-enterprise/130 (accessed 07.11.13).

[64] G. Neumann, S. Erol, From a social wiki to a social workflow system, in: D. $<$ ET AL $>$ Ardagna (Ed.), Business Process Management Workshops 2009, LNBIP 17, Springer, Heidelberg, 2009, pp. 698-708.

[65] C.J. Su, C.-Y. Chiang, Enabling successful Collaboration 2.0: a REST-based Web Service and Web 2.0 technology oriented information platform for collaborative product development, Computers in Industry 63 (2012) 948-959.

[66] D.R. Millen, J. Feinberg, B. Kerr, Dogear: Social Bookmarking in the Enterprise CHI06, Montréal, Canada, 22-27 April, 2006.

[67] K. Henttonen, Exploring social networks on the team level - a review of the empirical literature, Journal of Engineering and Technology Management 27 (2010) 74-109.

[68] B. Grabot, A. Mayere, R. Houe, F. Hémont, La longue route vers l'ERP 2.0, 9ème Congrès International de Génie Industriel, Saint-Sauveur, Québec, Canada, October $12-14,2011$.

[69] P. Dmitriev, N. Eiron, M. Fontoura, E. Shekita, Using Annotations in Enterprise Search, WWW 2006, Edimburgh, Scotland, 23-26 May, 2006.

[70] R. Dennison, BT 2.0 Case Study (2007), http://richarddennison.wordpress.com/btweb-20-adoption-case-study/ (accessed 07.11.13).

[71] M. Ferron, P. Massa, F. Odella, Analyzing collaborative networks emerging in Enterprise 2.0: the Taolin platform, Procedia Social and Behavioral Sciences 10 (2011) 68-78

[72] McKinsey, Building the Web 2.0 Enterprise, McKinsey Global Survery Results, The McKinsey Quarterly (2008, June).

[73] McKinsey, How companies are benefiting from Web 2.0, The McKinsey Quarterly (2009, June).

[74] McKinsey, Evolution of the networked enterprise, The McKinsey Quarterly (2013, March)

[75] P. Hofman, ERP is dead, long live ERP, IEEE Internet Computing 8 (2008) 84-88.

[76] Y. Wang, A. Greaseley, E. Thanassoulis, Combining ERP systems with enterprise 2.0, in enterprise information systems, Communications in Computer and Information Science 219 (2011) 198-207.

[77] D. Andersson, Enterprise 2.0 and Social Media Coming to ERP, 2010, http:// www.networkworld.com/news/2010/122010-enterprise-20-and-socialmedia.html (accessed 07.11.13).

[78] IFS, Enterprise 2.0 in Industrial ERP, Whitepaper, December, 2010

[79] J.C. Wortmann, A. Ittoo, Incorporating text in enterprise information system, in: IFAC Conference of Manufacturing Modelling, Management and Control, Saint Petersburg, Russia, June 19-21, 2013.

[80] V. Botta-Genoulaz, P.A. Millet, B. Grabot, A recent survey on the research literature on ERP systems, Computers in Industry 56 (6) (2005) 510-523.

[81] I. Nonaka, H. Takeuchi, The Knowledge Creating Company, Oxford University Press, Oxford, 1995.

[82] R.L. Ackoff, From data to wisdom, Journal of Applies Systems Analysis 16 (1989) 3-9.

[83] T.H. Davenport, L. Prusak, Working Knowledge: How Organizations Manage What They Know, Harvard Business School Press, Boston, MA, USA, 2000.

[84] G. Doumeingts, Y. Ducq, Enterprise modelling techniques to improve efficiency of enterprises, Production Planning and Control 12 (2) (2001) 146-163.

[85] M. Indulska, J. Recker, M. Rosemann, P. Green, Business process modeling: current issues and future challenges, Lecture Notes in Computer Science 5565 (2009) 501-514.
[86] R. Bergmann, Experience management: foundations, development methodology and internet-based applications, Springer-Verlag, Heidelberg, 2002.

[87] R. Studer, V.R. Benjamins, D. Fensel, Knowledge engineering: principles and methods, Data \& Knowledge Engineering 25 (1998) 161-197.

[88] S. Gudas, R. Brundzaite, Knowledge-based enterprise modelling framework, Lecture Notes in Computer Science 4243 (2006) 334-3436.

[89] E. Kimberling, ERP 2.0: Social Media and Enterprise Software, Blog, Published 19/ $11,2011$.

[90] I.T. Hawryszkiewycz, Perspectives for integrating knowledge and business processes through collaboration, enterprise, business-process and information systems modeling, Lecture Notes in Business Information Processing 50 (1-3) (2010) 82-93.

[91] A.W. Scheer, ARIS: Business Process Modeling, Springer, Heidelberg, 2000.

[92] J. Orlicky, G.W. Plossl, Orlicky's Material Requirements Planning, McGraw-Hill Professional, New York, 1994.

[93] Omg, Unified Modelling Language (UML), V2.4.1, 2011, August, http://www.omg.org/spec/UML/2.4.1/ (accessed 07.11.13).

[94] J.G. Breslin, D. O'Sullivan, A. Passant, L. Vasiliu, Semantic Web computing in industry, Computers in Industry 61 (8) (2010) 729-741.

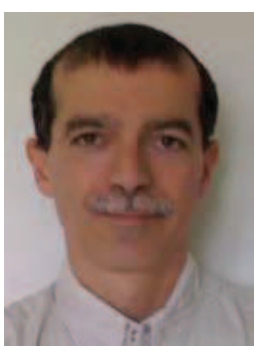

Bernard Grabot is Professor in the National Engineering School of Tarbes, France (ENIT). His research activities are oriented on supply chain management scheduling, competence management and decision support systems based on artificial intelligence tools. Pr Grabot is member of the IFAC working groups 3.2 "Computational Intelligence in Control" and 5.1 "Manufacturing Plant Control", and of the IFIP working group 5.7 "Advances in Production Management Systems". He has participated to several European projects (CRAFT, INTERREG, NOE etc.) and is the Editor in Chief of the IFAC journal "Engineering Applications of Artificial Intelligence". He also belongs to the editorial boards of "International Journal of Production Research" and "International Journal of Computational Intelligence Research".

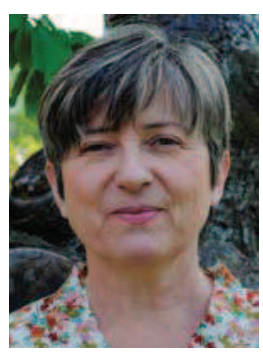

Anne Mayere is Professor in Information and Communication Sciences, University of Toulouse 3, and member of the research laboratory CERTOP, CNRS (www.certop.cnrs.fr). Her current research interests centre on the project of specifying the rationalization process of information production and communication activities and its equipment through information systems. On-going research fields deal with electronic patient records, telecare technologies, and the production of data concerning environment issues.

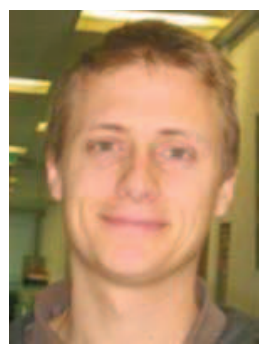

Fabien Lauroua has worked for 7 years in SAP cloud services, managing more than thirty cloud projects and helping his customers to define usages for web2.0 tools. $\mathrm{He}$ is one of the founders of Aldaïs, a company specialized in cloud project.

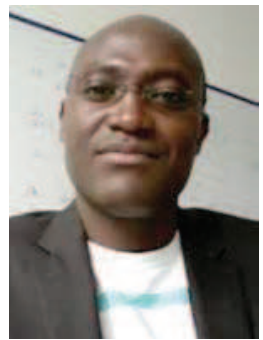

Raymond Houe After a PhD in industrial engineering in the field of industrial systems, Raymond Houe Ngouna is currently working on industrial issues of supply chains, which include consideration of human resources, with the perspective of information system, aiming at providing companies with operational decision support systems. Deeply involved in his laboratory (the LGP of ENI of Tarbes) in the activities of technology transfer, he is particularly interested in the new generation of web technologies. 